\title{
Adverse Effects of Fillers and Their Histopathology
}

\author{
Eckart Haneke, MD, $\mathrm{PhD}^{1}$ \\ ${ }^{1}$ Department of Dermatology, Inselspital, Universitätsspital Bern, \\ Bern, Switzerland \\ Facial Plast Surg 2014;30:599-614.
}

\begin{abstract}
Address for correspondence Eckart Haneke, MD, PhD, Department of Dermatology, Inselspital, Universitätsspital Bern, Freiburgstrasse 14, 3010 Bern, Switzerland (e-mail: haneke@gmx.net).
\end{abstract}

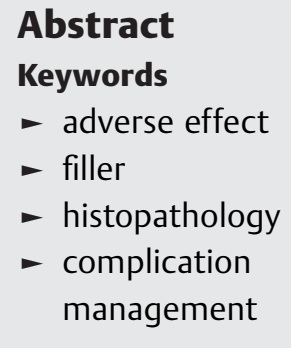

Filler injections belong to the most frequently performed beautifying procedures in cosmetic medicine. Untoward adverse effects are a catastrophe for the affected person and everything possible must be done to avoid them. This starts with a careful and thorough patient history concerning previous injections, potential symptoms of body dysmorphic syndrome, allergies, immune reactions and diseases, drug treatments, particularly those with an immunomodulatory potential, and chronic infections as well as a family history as to serious diseases, so-called collagenoses, immune defects, genetic disorders, and others. It is well known that some fillers are not well tolerated when injected next to another one.

Filler adverse effects can be classified according to their time course and because of user dependent, filler and host factors. $^{1,2}$ Technical errors concern too much or too little volume, incorrect depth of filler placement, wrong location, and inappropriate product choice. ${ }^{3}$

The physician injecting the filler must, of course, be experienced to avoid gross mistakes concerning the site of injection, the volume, the speed, the depth, etc., as well as the postinjection treatment. The physician should be available after the injection and never dismiss a patient's concerns. The nature of complication is checked and can be classified into light and disappearing by itself, moderate and requiring treatment, or severe necessitating immediate intervention. Treating a patient with empathy has avoided many law suits.

Concerning the fillers themselves, it is the substance and its chemistry, its purity, homogeneity, particle size, shape and roughness, ${ }^{4}$ its electrical charge, its ability to biointegration

Issue Theme Filler Complications; Guest Editor, Eckart Haneke, MD, PhD and to react with other substances that matter. It has also to be kept in mind that a filler result that is desirable at the age of 20 years might look odd at age 50 or 60 years. And finally, the host and his or her immune system are of paramount importance. This can change during the life of a filler and have a great impact on its tolerability.

\section{Time Course of Filler Effects}

Fillers are divided into reversible (early or temporary: collagens and hyaluronic acid [HA]; late or long-term: HA with dextranomer beads, poly-L-lactic acid [PLL] and calcium hydroxylapatite), and irreversible (delayed or permanent ones: paraffin, silicon preparations, polymethyl methacrylate microspheres, hydroxyethyl methacrylate fragments, polyacrylamide hydrogel, polyalkylimide gel, polyvinyl hydroxide microspheres in polyacrylamide gel, and many more). In general, their adverse effects last as long as their intended ones. ${ }^{5}$ Although it is often thought that temporary fillers are better tolerated than permanent ones, this is apparently not true as the frequency of shortterm adverse reactions is very similar. In fact, whatever substance is injected into the tissue, it is perceived as a foreign substance with an initial challenge to the host's immune system. The famous injections of the patients' own blood had a nonspecific immunostimulatory effect as even this was a short-term challenge to the immune system.

Early complications develop within less than 2 weeks and include erythema, edema, and allergy. Bumps and lumps following superficial injection are usually visible immediately
Copyright (C) 2014 by Thieme Medical Publishers, Inc., 333 Seventh Avenue, New York, NY 10001, USA. Tel: +1(212) 584-4662.
DOI http://dx.doi.org/ 10.1055/s-0034-1396755. ISSN $0736-6825$. 
after the injection or shortly thereafter. Necrosis because of intra-arterial injection becomes obvious within a day.

Late complications are chronic inflammation, late allergic reactions, nodules (granulomas) and filler migration, hypertrophic scars, and telangiectasia. ${ }^{6}$

Delayed complications are considered to be largely because of biofilm formation although this is still disputed. ${ }^{7}$

Often, adverse effects develop weeks, months, or even years after the injection, and the patients frequently do not remember which filler they had gotten. The problem may even be confounded by the fact that different fillers may have been injected at various times by different physicians and even sometimes by nonphysicians.

Immediate reactions such as adequate pain after procedure, mild bruising, redness, and some edema are normal and are not complications. They can often be avoided by cooling the injected area, and this is also the most common treatment. Pain can be reduced by local anesthesia, slow injection, and low volume. Aloe vera, arnica, or vitamin K creams are recommended to reduce or avoid bruising. Bleeding and ecchymoses are rare when blunt cannulas are used. Swelling depends on the substance used, the localization of the injection, the amount, and the individual tolerance. Again, cooling usually reduces the swelling.

Vascular compromise may be the consequence of arterial or venous obstruction, which in turn may be because of intravascular injection of the filler, direct pressure of the filler on the vessel wall, or indirect trauma to the vessel wall. Particular attention has to be paid during glabella and nasal ala injections where inadvertent intravascular filler injection may result in necrosis and even blindness when the retinal artery is occluded. ${ }^{8,9}$ Whenever blanching is seen during the injection this must immediately be stopped. ${ }^{10}$ In case of HA, hyaluronidase is injected as close to the site of intravascular injection as possible. Whether aggressive massage, warm compresses, and nitroglycerin application are really helpful for other fillers remains to be seen. ${ }^{11-13}$ Intravascular injection is virtually impossible when using a blunt cannula. ${ }^{14}$

Late complications are infection, granuloma formation, scarring, and loss of function. Infection may be because of insufficient disinfection of the treatment area, injection into or through an oily skin or makeup or into an infected region. ${ }^{15}$ Infection can develop into a major problem when particulate permanent fillers are used that may develop a bacterial biofilm on the surface of the particles. Although cellulitis promptly responds to systemic antibiotics biofilms are usually resistant to antibiotics and require complete removal of the filler. ${ }^{16}$ Granulomas are another serious problem. There are some general rules as to their development: nonparticulate substances rarely produce granulomas with the exception of silicon, but all the particles may induce granulomas. The frequency of granulomas is the higher the bigger the surface is in relation to the volume, the sharper the edges of the particles are, that is, crystalloid particles are much more likely to induce granulomas independent of the longevity of the particles. PLL acid is a slowly dissolving crystalloid compound that caused several granulomas, particularly, at the time when the recommendation to reconstitute it with a small volume of saline was followed by the users. ${ }^{17}$ Although some permanent fillers are advertised as being gels they may consist of small polygonal particles, such as polyacrylamide gel (PAAG) or hydroxyethyl methacrylate (DermaLive and DermaDeep; Dermatech, Paris, France).

Delayed reactions are thought to be because of bacterial biofilms. ${ }^{18}$ They may induce granulomas as well as so-called cold abscesses. This is the reason why granulomas should not be injected with corticosteroids as the first therapy but rather be treated with antibiotics for at least 14 days.

\section{Classes of Soft Tissue Fillers}

\section{General Remarks}

Many different agents are available. Some have the same or very similar names and are chemically different whereas some popular substances are sold under many different brand names.

The same agents may display different behavior, due to variations in the production process, different molecular size, and variable protein moieties. This is particularly the case of the innumerable HA products.

The clinical appearance of adverse effects of the various products does not usually allow for identifying the filler used, as they are in most cases not filler specific.

Soft tissue fillers are subdivided into the following:

- Human substances

- Biologic agents

- Synthetic products

Be aware that "biological" does not automatically mean degradable and that "biodegradable" is not a guarantee that the human body has the necessary enzymes to digest this filler.

\section{Autologous Fat}

Autologous fat is the prototype of a human substance and is often thought of as being without adverse effects. However, fat injections also have potential adverse effects. They are because of collecting the fat, fat storage or injection and reach from rapid disappearance to infection and even death due to inappropriate injection technique. ${ }^{19}$

\section{Collagen}

A great number of biologic substances are on collagen basis: human collagen, bovine collagen, and porcine collagen with bovine collagen having been the first commercially available product, for example, Zyderm (McGhan Medical Corp., Fremont, CA). The degree of cross-linking and the chemical used for it also influence the tolerability of collagen fillers. ${ }^{20}$

It was thought that human collagen would have an advantage as it does not require preinjection tests as bovine collagen. However, it turned out that apart from the allergic reactions, the human collagen has virtually the same life span and may be associated with as strong inflammatory reactions as bovine collagen. ${ }^{21}$ In contrast, morselled autologous dermis appeared to be very well tolerated with only transient inflammatory reaction during the wound-healing phase and 
effective revascularization. ${ }^{22}$ Collagen is also synthesized by cultured fibroblasts (Cosmoderm [Advanced Tissue Sciences, San Diego, CA] with $35 \mathrm{mg} / \mathrm{mL}$, Cosmoderm with $65 \mathrm{mg} / \mathrm{mL}$, and Cosmoplast with $35 \mathrm{mg}$ of glutaraldehyde-stabilized human collagen $/ \mathrm{mL}$ ). Human collagen from cadaveric dermis (Dermalogen [Collagenesis, Inc., Beverly, MA] and Cymetra [Life Cell Corp, Branchburg, NJ]) is available, too. Human collagen is also produced by injected fibroblasts (Isolagen [Fibrocell Science Inc., Exton, PA]). They are cultured and expanded from a small biopsy of the patient and reinjected. Although said to give good results the procedure of taking a biopsy, sending it to a specialized laboratory, waiting 6 to 8 weeks until getting the expanded cells and the high cost have prevented it from becoming a popular method.

Porcine collagen was found to last longer and be better tolerated than bovine collagen and not require pretesting. ${ }^{23,24}$ However, lip injection is discouraged. ${ }^{25}$

\section{Hyaluronic Acid}

HA is a linear, unbranched, high-molecular-weight glycosaminoglycan, consisting of alternating D-glucuronic acid and $\mathrm{N}$-acetyl-D-glucosamine. As a biologic substance without species specificity, it should, in principle, be tolerated by all the living organisms. However, the natural glycosaminoglycan moiety is linked to species-specific proteins and also the production process is critical. HA is not only a biologic and naturally occurring filler, but it also has a variety of different biological effects that depend on its molecular size. ${ }^{26}$ Small fragments are proinflammatory whereas long chains inhibit inflammation. ${ }^{27-29}$ For its use as a filler, it has to be stabilized and the way and degree of stabilization are also important for the tolerability of HA. ${ }^{30}$ The more HA is cross-linked and thus stable the more its tolerability is reduced.

\section{Perhydrosqualene and Collagen-Polyvinylpyrrolidone}

This has recently been proposed as a filler for deep nasolabial folds with a lifetime of 12 to 18 months. It was claimed that no significant adverse effects were seen. ${ }^{31,32}$

\section{Polycaprolactone}

Polycaprolactone-1 (PCL-1) dermal filler (Ellansé, AQTIS Medical, Utrecht, the Netherlands) is a soft tissue dermal filler based on PCL microspheres. The totally smooth spherical-shaped PCL microspheres (range, 25-50 $\mu \mathrm{m}$ ) are homogenously suspended in a tailor-made aqueous carboxy methylcellulose (CMC) gel carrier. PCL in CMC has been widely used in many medical devices. It is totally biodegradable, nontoxic, and completely excreted from the human organism. The CMC gel carrier is gradually resorbed by macrophages over a period of several weeks, during which the PCL microspheres trigger a natural response of the skin and stimulate a natural wound-healing process with neocollagenesis. The new collagen replaces the volume of the resorbed carrier. The microspheres are not phagocytosed because of their size and surface characteristics. The PCL dermal filler is indicated for deep dermal and subdermal implantation including hand rejuvenation. Adverse effects were not (yet) reported. ${ }^{33,34}$
Biologic, but Not Enzymatically Degradable by Humans

Alginate-derived mannans were thought to offer advantages over other short-lived biological fillers because of their ease of injection and lower tendency to cause swelling as compared with HA, but they soon turned out to have a high rate of adverse effects, particularly granuloma formation. ${ }^{35}$ Less than half a year after its launching the product was withdrawn from the market.

\section{Long-Lasting Fillers}

The currently used fillers with a long-lasting effect are PLL and calcium hydroxyl apatite (CHA). The former has been used for more than half a century as suture and other material in surgery and proven to be well tolerated. CHA has been used as bone cement with good effect. However, both substances are different in particle size and shape when injected as fillers for soft tissue augmentation. Granulomas were observed after PLL injections and rarely after CHA.

\section{Permanent (Irreversible) Fillers}

There is a huge number of different substances that had been or are still in use for soft tissue augmentation. The main classes comprise polymethyl methacrylate (Arteplast [Suneva Medical, San Diego, CA], Artecoll [Artes Medical Inc., San Diego, CA], Artefill [Suneva Medical], Metacrill [Nutricell, Rio de Janeiro, Brazil], and Metrex [Nutricell]), methacrylate fibers (Procell [ProCell Therapies, Clearwater, FL]), acrylic hydrogel (DermaLive, DermaDeep), PAAG (Amazing gel [NanFeng Medical Science and Technology Development Co., Ltd., Shijiazhung, China], Aquamide [Contura International, Söborg, Denmark], Argiform [Bioform Corp., Moscow, Russia], Bioformacryl [Progen, Ancona, Italy], Evolution [ProCytech SA, Bordeaux, France], Formacryl [Progen], and Outline [ProCytech SA]), polyethylene beads (Profill [Laboratoires Filorga, Paris, France]), polyalkylamide (Bio-Alcamid [B\&B Dental SRL, Polymekon, Italy]), solid silicone particles in polyvinylpyrrolidone (Bioplastique [Netherlands]), polydimethylsiloxane (Biopolimero [Spain] and Biopolymere [Biocell Laboratories, Lichtenstein, Germany]), silicone oil (medical grade silicone oil), polymeric compound of natural silica and oxygen (Dermagen [Dermagen Inc., Fullerton, CA]), polyoxyethylene fatty acid and elastin copolymer gel (Kopolymer 4E [Switzerland]), methacrylate and copolymer 4-G (Rhegecoll [Switzerland]). Some are illegal in the United States and the European Union, others have been withdrawn from the market for several years, but they continue to induce granulomas and other severe adverse effects. Chemically similar or even identical substances are marketed as different particle size and shape and exhibit very different adverse effect profiles.

\section{Adverse Effects}

Many adverse effects are not specific for a particular filler but may be ascribed to the volume augmentation or to technical faults such as wrong indication, placement site, wrong injection needle, ${ }^{36}$ and infection due to contaminated ice or water. ${ }^{37}$ Infections can best be differentiated from other nodules and granulomas by radio-labeled leukocyte scintigraphy. ${ }^{38}$ Late-onset adverse effects are often inflammatory 
and immune mediated. Edema, granulomas, ${ }^{39}$ sarcoid-like reactions, and panniculitis are the findings most commonly seen. Systemic granulomatous and autoimmune diseases, and even less frequently, acute hypersensitivity reactions are rarely seen. ${ }^{40}$

\section{Autologous Fat}

Adherence to key principles, including sterile technique and low-volume injection throughout layers of tissue, is critical in obtaining excellent results. Adverse outcomes are infrequent. However, early adoption of surgical procedures by those without a sound understanding of the underlying principles and techniques can have disastrous consequences. Furthermore, physicians operating on any patient must understand the potential for complications and be able to manage these appropriately when they occur. ${ }^{41}$ Fat longevity is dependent on handling and preparation of the fat. Poor fat viability produces an inadequate result and has thus to be considered as a complication. ${ }^{42}$ On the contrary, deterioration of the esthetic results after a significant weight gain because of corticosteroids, oral contraception, and a change of lifestyle was seen in a patient with Romberg syndrome. ${ }^{43}$ Lipomodeling of the breast was performed in 880 cases, approximately $140 \mathrm{~mL}$ had to be injected for a desired volume of $100 \mathrm{~mL}$, which remained stable for 3 to 4 months. No radiological problems at mammography were observed after the procedure. Fat necrosis occurred in only 3\%, but serious complications included one case of infection at the harvest site, six cases of infection at the injection site, and one case of intraoperative pneumothorax. ${ }^{44}$ Furthermore, there are case reports on an abscess formation, life-threatening sepsis, and residual deformity. ${ }^{41}$ Neurological complications were repeatedly reported by two patients developing unilateral loss of vision after fat injection into the glabella, two patients with loss of vision, aphasia, and hemiparesis, and one patient developing sensorimotor hemiparesis after infarction of the middle cerebral artery. ${ }^{45-48}$ Death after autologous fat grafting occurred in a 20-year-old women with a decade of lupus profundus and hereditary C4 complement deficiency who had already got three fat injections from 1997 to 1999 with approximately 50\% resorption. A flare of her lupus profundus in 2007 resulted in loss of most of the injected fat despite treatment with thalidomide $25 \mathrm{mg}$ and prednisolone $7.5 \mathrm{mg}$ daily. After donor site tumescent anesthesia and bilateral infraorbital blocks for recipient sites, $35 \mathrm{~mL}$ fat were injected with minimal pressure using an 18-gauge sharp needle because of scarring of the recipient site. There was dizziness immediately after injection of the left cheek and a vasovagal syncope suspected and the patient placed in supine position. Another $35 \mathrm{~mL}$ of fat was subsequently injected. The patient became increasingly unwell over the next 2 hours, eventually developed progressive refractory hypoxic respiratory failure and cardiovascular decompensation. Despite emergency treatment in a critical care unit, she developed fulminant pulmonary edema, right ventricle dilatation, and died because of cardiac arrest 4 hours after fat transfer. ${ }^{19}$ Whether or not using a blunt cannula would have prevented the death of this patient is not clear. Apparently, these adverse effects were technique dependent and not due to the substance.

Liposuction is often used to collect fat and is a very safe procedure when performed under tumescent anesthesia. Infection, bruising, hematoma, and seroma are rare. Fat embolism is very rare when not too much is aspirated and liposuction is not associated with other cosmetic procedures. Most of the serious complications were associated with general anesthesia.

\section{Human Collagen}

Autologous human collagen is well tolerated, both when derived from cultured fibroblasts as well as autologous
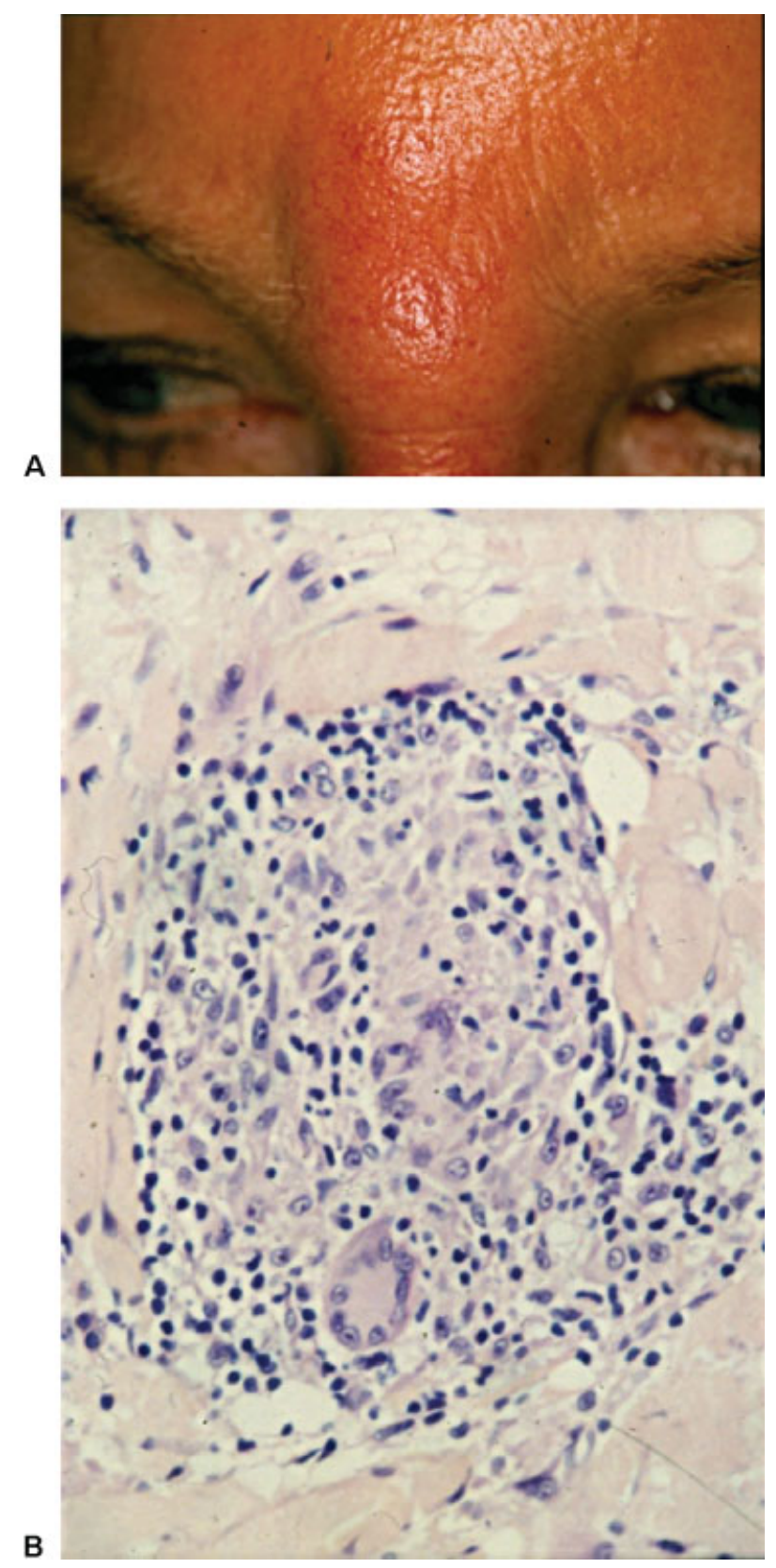

Fig. 1 (A, B) Long-lasting, virtually persistent granuloma formation due to collagen (Zyderm); clinical picture and histopathology of a granuloma (Courtesy: A. De Coninck, Belgium). 
injectable dermis. ${ }^{22}$ Human allogeneic collagen was observed to elicit acute to subacute inflammatory reactions ${ }^{49}$ but no serious long-term adverse effects were reported. The cosmetic effect lasts between 4 and 7 months.

\section{Nonhuman Collagens}

They are foreign proteins with a propensity to induce allergies and granulomas, particularly bovine collagen whereas human and porcine collagens are better tolerated. The adverse effects are usually temporary until all collagen has been resorbed, but one case was observed with stone-hard granulomas not disappearing with any treatment over more than a decade (A. De Coninck MD, personal oral communication, 2008). Usually, the granulomas are palisaded around amorphous eosinophilic material representing bovine collagen ( $\mathbf{- F i g . 1} \mathbf{1}$ ). This is characterized by very thick bundles, pale gray-violet staining with Masson trichrome stain, and lack of birefringence. ${ }^{50}$ Whether the injection of collagenase ${ }^{51}$ would be successful has not yet been tried. The most common adverse effects were temporary granulomas at the site of injection in approximately $4 \%$ of the patients. Testing and double testing before treatment were recommended, but nevertheless, granulomas did occur.

Collagen fillers are now used less and less frequently and adverse effects are expected to be seen rarely.

\section{Hyaluronic Acid}

HA is universally present in all animal species. It is said to be non-species specific; however, hyaluronans are linked to proteins that are species specific. Good preparations are (almost) free from foreign proteins. They have a low propensity to induce granulomas, but they show a variety of transitory adverse effects, including rare granulomas and infection. ${ }^{52,53}$ At present, there are probably almost 200 preparations on the market. To prevent untoward adverse effects well-known brands with high quality should be preferred as their complication rate has been shown to be much lower.

Untested cheap products should never be used.

HA preparations are currently the most widely used fillers with a longevity of approximately 6 months, but this is highly variable depending on molecular size and cross-linking. There are differences among them concerning the size of the molecule, the protein content, the chemical bonding, the fluidity, whether they are monophasic or biphasic, injection pain, and longevity. ${ }^{54}$ A good preparation must not clump as this may give rise to granulomas (-Fig. 2). Although granulomas were not rare at the beginning of the non-animal-derived synthetic HAs, they are now exceptional, except for a new product marketed roughly 3 years ago. This induces foreign body giant cell granulomas with a high content of eosinophils, and HA can be seen in giant cells (- Fig. $\mathbf{3}$ ).

Also in the early period of HA fillers, reactions interpreted to be hypersensitivity were observed. ${ }^{52,55,56}$ Very rare adverse effects are a multiform rash and systemic anaphylactoid reactions ${ }^{57}$ after intra-articular injection of $\mathrm{HA},{ }^{58}$ with native HA having a lower sensitizing potential. ${ }^{30}$
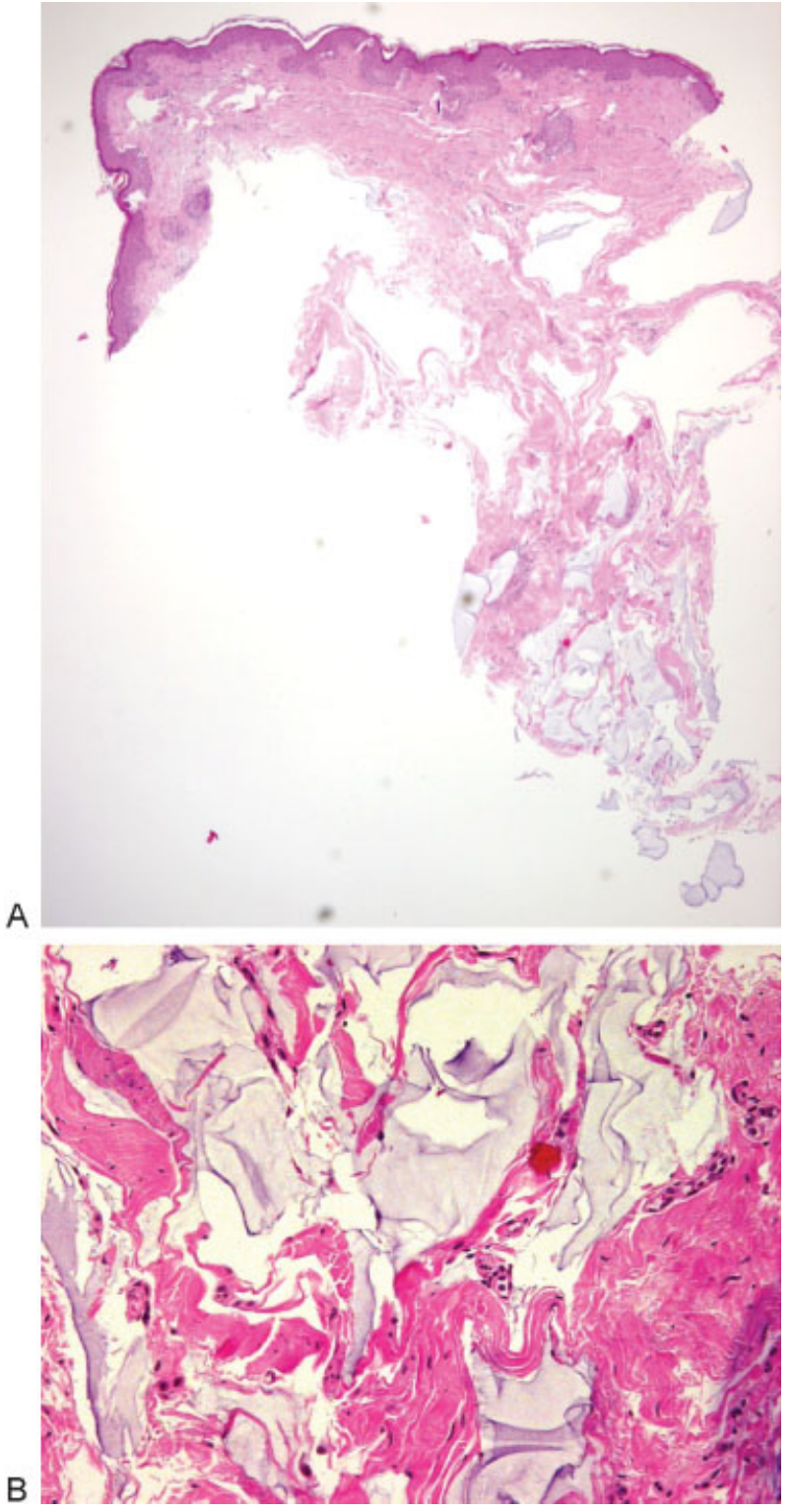

Fig. 2 (A) Hyaluronic acid in the dermis: There was a slightly bluish to skin colored nodule (Tyndall effect) that had been biopsied under the suspected diagnosis of a basal cell carcinoma. A filler had been injected 5 years before the biopsy. There is no inflammatory infiltrate. Scanning magnification, hematoxylin-eosin (HE) stain. (B) A close-up shows hyaluronic acid in the dermis without any inflammatory reaction. HE, $\times 200$.

Adverse effects because of the substance are usually shortlived and can be repaired by injecting hyaluronidase. The dose depends on the specific drug and may also vary according to the HA used and its degree of cross-linking. This enzyme cleaves both natural as well as cross-linked HA. Three sources available are as follows: bovine, ovine, and recombinant. As they are proteins, they have the potential of causing an anaphylactic shock in sensitized individuals. It is therefore necessary to question the patient about possible allergies. Hyaluronidase has also been used to treat HA granulomas. ${ }^{59}$

Technique-dependent adverse effects may occur as with other fillers. When HA is injected too superficially, it may shine through with a bluish-grayish color, giving rise to the 

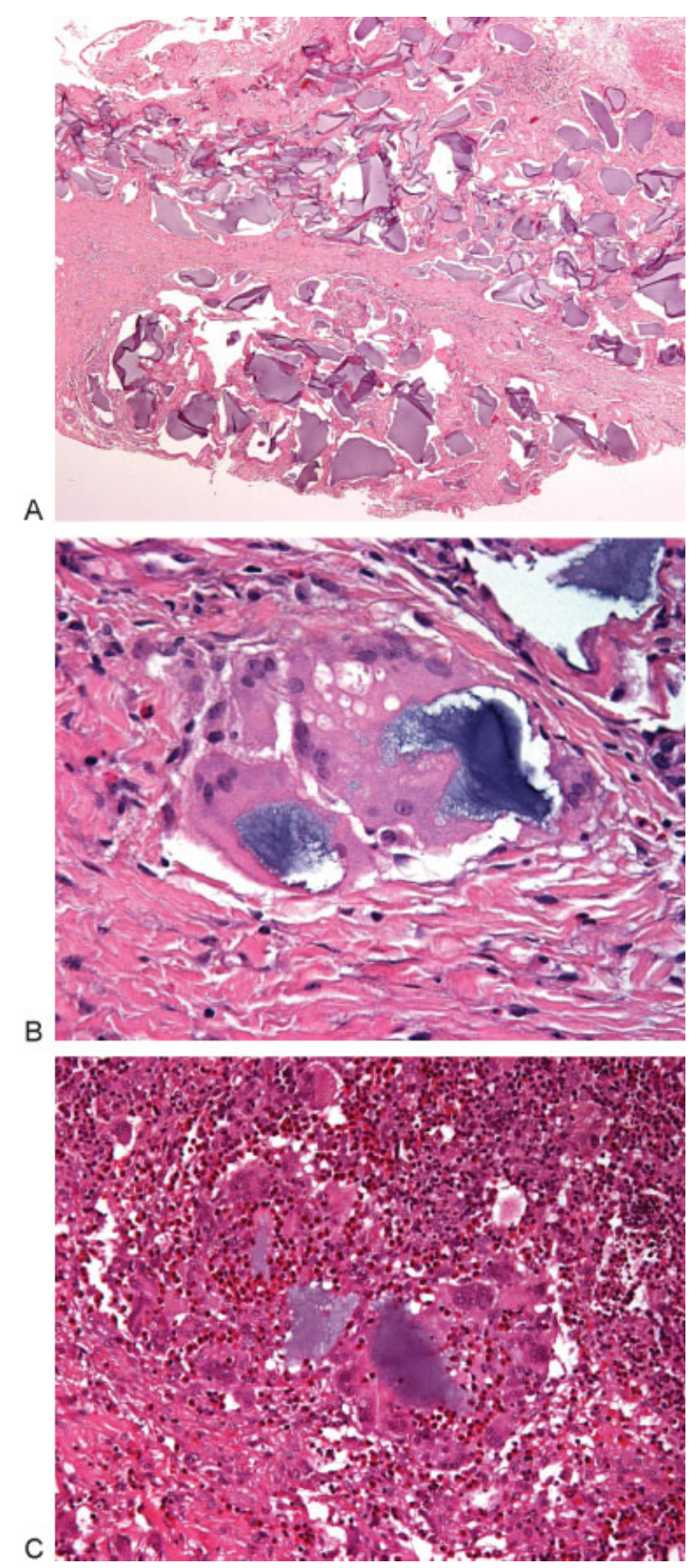

Fig. 3 (A) Inflammatory and granulomatous reaction to hyaluronic acid (Hylacorp [BioScience GmbH, Ransbach-Baumbach, Germany]). $\mathrm{HE}, \times 100$. (B) Foreign body giant cells engulfing clumped hyaluronic acid (Hylacorp). (C) Epithelioid cells, foreign body giant cells with ingested hyaluronic acid (Hylacorp) and a very dense eosinophilic infiltrate.

so-called Tyndall effect. It has to be used with care in the eyelids as it may cause swelling due to its ability to attract water. Accidental intracapillary injection may cause livedo reticularis. ${ }^{52,60}$

Histopathology of grayish-glassy nodules after superficial injection just show HA deposits without any further tissue changes (-Fig. 2). Granulomas may show a very dense lymphocytic infiltrate with abundant eosinophils and many foreign body giant cells often containing basophilic amorphous material that corresponds to HA ( - Fig. $\mathbf{3}$ ).

A middle-aged woman was seen with widespread swelling in the glabella, central ocular, and nasal regions after she had injected herself with a diluted HA-containing cream for topical use; histopathology showed a "Swiss cheese like" picture similar to that after vaseline injection; this adverse effect was most probably not due to the HA component in the abused topical preparation (unpublished personal observation).

\section{Alginate}

An alginate derived filler (Novabel CellMed AG, Merz Pharmaceuticals, Frankfurt am Main, Germany]) was marketed as a new biologic filler with prolonged augmentation effect; however, very shortly after its marketing, granulomas were observed $^{61}$ and it was withdrawn from the market. The granulomas start with erythema and swelling until hard nodules form 2 to 5 months after injection. Ultrasound shows hypoechoic structures surrounded by a hyperechoic rim. Histopathology demonstrates spherical basophil structures of 100 to $120 \mu \mathrm{m}$ in diameter enveloped by a prominent rim of giant cells. The granulomas are surrounded by a distinct hyaline collagen capsule. ${ }^{61}$

\section{Hyaluronic Acid Plus Dextranomer Microspheres}

The dextranomer beads are added to the HA to improve the longevity of the filler. They consist of cross-linked dextran molecules with a positive surface charge and a diameter of 80 to $120 \mu \mathrm{m}$. They attract macrophages releasing tumor growth factor $\beta$ and interleukins, which stimulates collagenesis around the dextranomer beads, maintaining the volume correction effect after the resorption of HA.62 The material is apparently well tolerated with only a few reports of granulomas ( - Fig. 4), one of which was suppurative ${ }^{63}$ and the other ones were foreign body giant cell rich. $^{64,65}$ In histopathology, the dextranomer beads stain dark bluish or

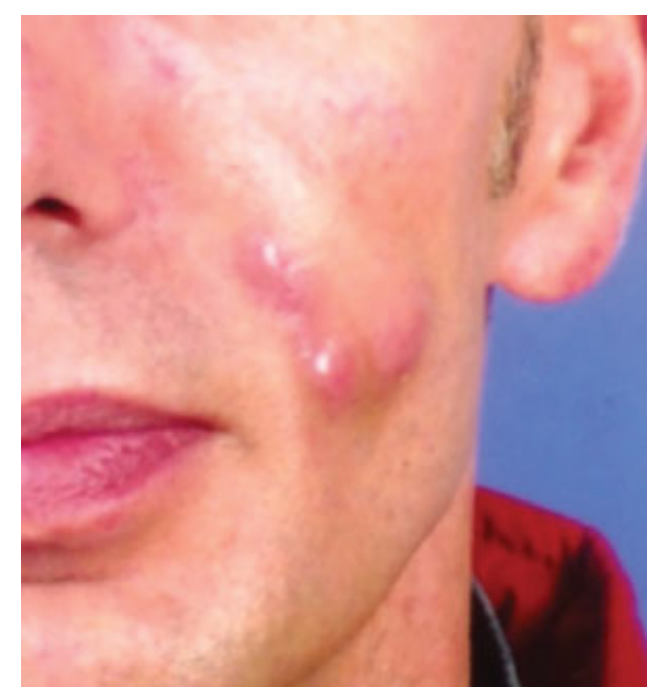

Fig. 4 Sterile suppurative granulomas due to Matridex (Courtesy: G. Feller-Heppt, Germany). 
purplish, or may even look like empty spaces giving a "Swiss cheese" aspect. Incision of the nodules and treatment with cephalexin and methylprednisolone aceponate led to complete resolution in one case. ${ }^{63}$

\section{Poly-L-lactic Acid}

This substance has been used for decades in medicine and surgery and was well tolerated. In contrast, PLL as a filler comes as a powder of crystalloid particles that has to be reconstituted before injection. Subcutaneous nodules are either fibrotic or granulomas. They can form because of insufficient time during reconstitution of the material, inadequate dilution, overcorrection, superficial injection techniques, or inappropriate concentration of PLLA molecules secondary to muscle movement, and granulomas are thought to be because of allergic or inflammatory host responses. ${ }^{66} \mathrm{In}$ the early years, the recommendation was to use $3 \mathrm{~mL}$ : this turned out to cause granulomas and also often clogged the injection needle. Now, most physicians use $10 \mathrm{~mL}$ or more of physiologic saline, often with some lidocaine added. After injection, the water is resorbed and the PLL particles induce a fibroblastic reaction lasting for 24 months or longer. This may cause fibrotic nodules, which may be visible in thin skin such as around the eyes and in the hands, ${ }^{67}$ and the substance may clump in the lips; these are the adverse effects of faulty technique (-Figs. 5 and $\mathbf{6}$ ). PLL granulomas are classical giant cell granulomas with many epithelioid cells and relatively few lymphocytes. The PLL particles are oval, fusiform, or spiky and seen in epithelioid and giant cells as well as in between (-Fig. 7). They are birefringent in polarized light. ${ }^{17}$ The granulomas last at least 18 months. ${ }^{68}$

\section{Calcium Hydroxyl Apatite}

CHA is an inorganic material and has long been used successfully as bone cement. The currently available preparation is Radiesse (Bioform Medical Inc., San Mateo, CA), which consists of microspheres (30\%) of 25 to $45 \mu \mathrm{m}$ suspended in a gel made of water, glycerol, and sodium carboxy methylcellulose (70\%). It is inert and nonantigenic, but it stimulates collagen production. It is very well tolerated when injected as a

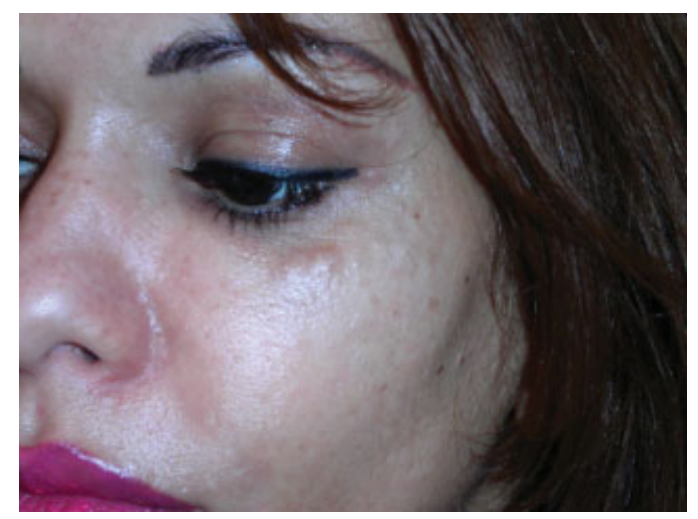

Fig. 5 Poly--lactic acid (Newfill [Dermik Laboratories, Berwyn, PA]) was injected too superficially and in a thin skin giving rise to a palpable and visible nodule (Courtesy: P. André, France).

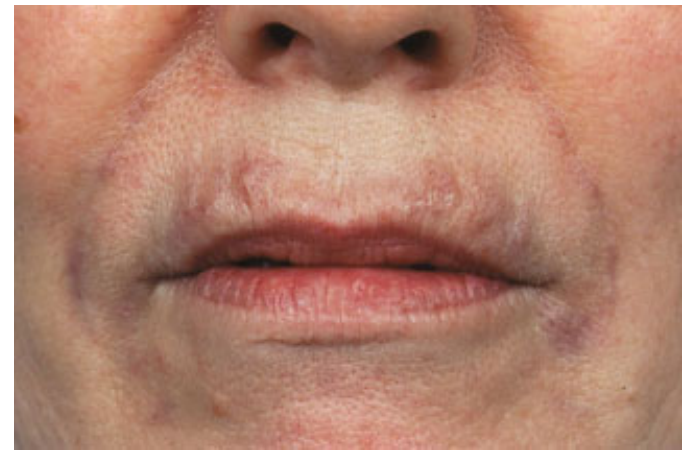

Fig. 6 Granulomas and nodules due to poly--lactic acid (NewFill) (Courtesy: F. Bruyns, the Netherlands).

suspension for soft tissue augmentation. The duration of the correction is between 9 and 12 months, ${ }^{69}$ but it may also be longer. Most adverse effects are because of technical faults. Particularly when injected into the lips, it tends to clump and produces palpable nodules. In one study, postinjection cellulitis was observed at a frequency of $1.7 \%{ }^{70}$ However, granulomas also occur with a higher frequency in elderly women. ${ }^{71}$ They consist of tightly packed, dark bluish

A
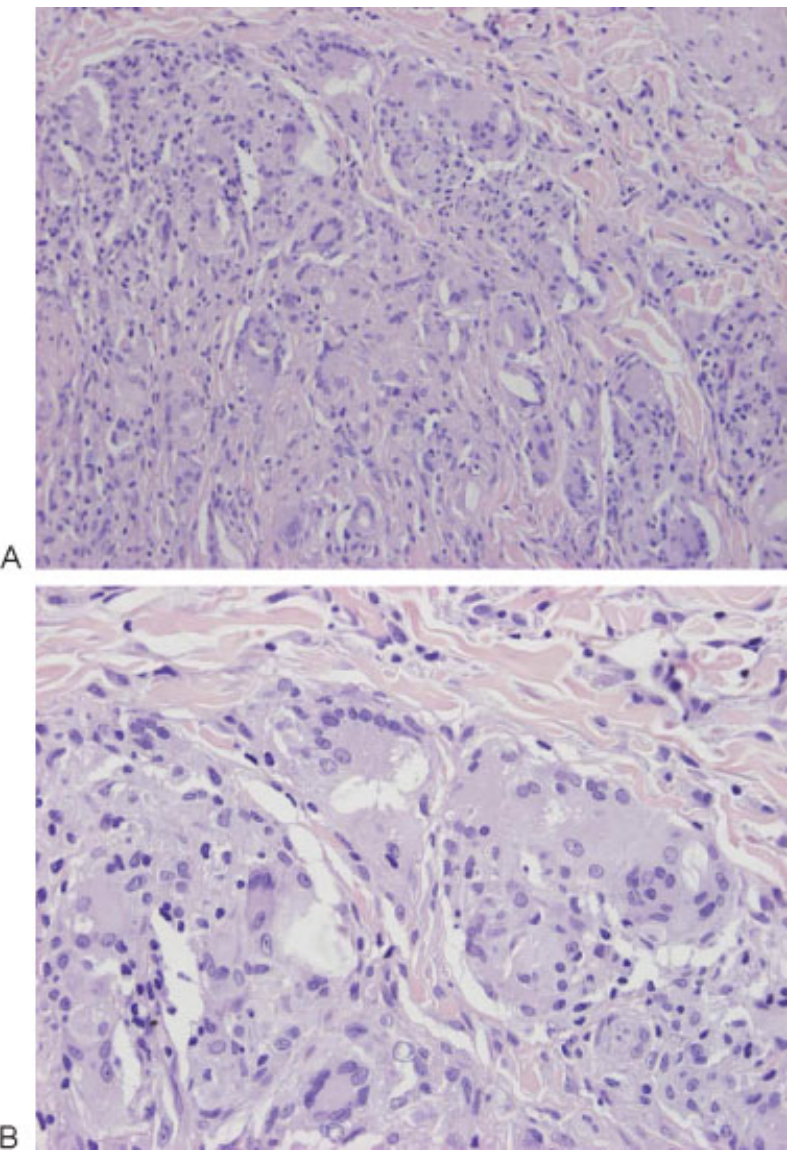

Fig. 7 (A) Granuloma formation due to poly-Llactic acid (PLL) (NewFill). There are mainly epithelioid and foreign body giant cells. The latter often engulfed crystalloid PLL particles. Hematoxylin-eosin (HE), $\times 200$ (Courtesy: F. Bruyns, the Netherlands). (B) High magnification of a PLL granuloma. HE, $\times 400$. (Courtesy: F. Bruyns, the Netherlands). 
microspheres with a diameter of 25 to $40 \mu \mathrm{m}$ and giant cells. ${ }^{72}$ The nodules were shown to rapidly decrease after fractional $\mathrm{CO}_{2}$ laser treatment. ${ }^{73}$ Recently, a grade 3 systemic reaction was observed 30 minutes after injection of $\mathrm{CHA}$ vocal cord filler prompting the authors to recommend a 30-minute postprocedure observation period. ${ }^{74}$

\section{Polyacrylamide Gel}

PAAG is a suspension of $2.5 \%$ to $5 \%$ PAAG in sterile water. It is marketed under many different names: PAAG (Sinocos Eastcos, Hong Kong, China), Amazing gel, Aqualift, Aquamid (Contura International, Søborg, Denmark), Argiform, Bioformacryl, Formacryl, and Outline, which are slightly different in minute additional components. ${ }^{1}$ The material is widely resistant to enzymatic degradation and phagocytosis. The particles can harbor bacteria on their surface and give rise to late infections, biofilms, and abscesses. ${ }^{75}$ It is claimed not to induce allergic reactions or to interfere with the hemodynamic system. It can hold 300 to 400 times its weight in water. It was widely used for breast augmentation in Eastern countries. The results are immediate and overcorrection is necessary. Its major advantage is that it remains soft and pliable after injection. ${ }^{76}$ However, the products should not be injected over other ones. PAAG is generally well tolerated, but severe adverse effects have also been described, for example, swelling, lumps, abscesses, facial disfigurement, gel dislocation, and respiratory distress. ${ }^{77}$ Breast deformity, lumpiness, intermittent swelling, pain, and gel extrusion were observed in other series. ${ }^{78-80}$ The gel is exceedingly biocompatible and thus an excellent medium for bacteria. ${ }^{81}$ The main risk is infection frequently developing after 8 to 12 months or even later, but cultures often remain negative and only polymerase chain reactions could identify the bacteria that are normally not pathogenic, such as Propionibacterium acnes, Streptococcus oralis and mirabilis, Staphylococcus aureus, and some atypical mycobacteria. Histopathology shows foci of neutrophils and karyorrhectic material, numerous macrophages, and foreign body giant cells around a gel that appears somewhat similar to HA. Often giant cells contain vesicles full of PAAG and the material frequently shows small empty blebs both in the giant cells as well as when present in large lakes (-Fig. 8). PAAG is positive with Alcian blue and not birefringent.

\section{Polyalkylimide Gel}

Polyalkylimide gel $4 \%$ in water (Bio-Alcamid, Polymekon, Milan, Italy) is another large volume filler to be injected into the deep dermis or under the dermis. A thin collagen capsule forms after injection preventing migration and keeping it apart from the surrounding tissue. Aspiration or punching a small hole over it permits its removal. Adverse effects were edema, bruising, nodules, infections, severe inflammatory reactions, migration despite the capsule-like fibrosis around it, unsatisfactory appearance and late-appearing abscesses. Migration is a rare event. ${ }^{82}$ Histopathology shows basophilic amorphous material surrounded by neutrophils and erythrocytes. Gram stain may reveal bacteria. The infections are very difficult to treat and require high-dose long-term antibiosis, incision, drainage, and irrigation. ${ }^{83,84}$
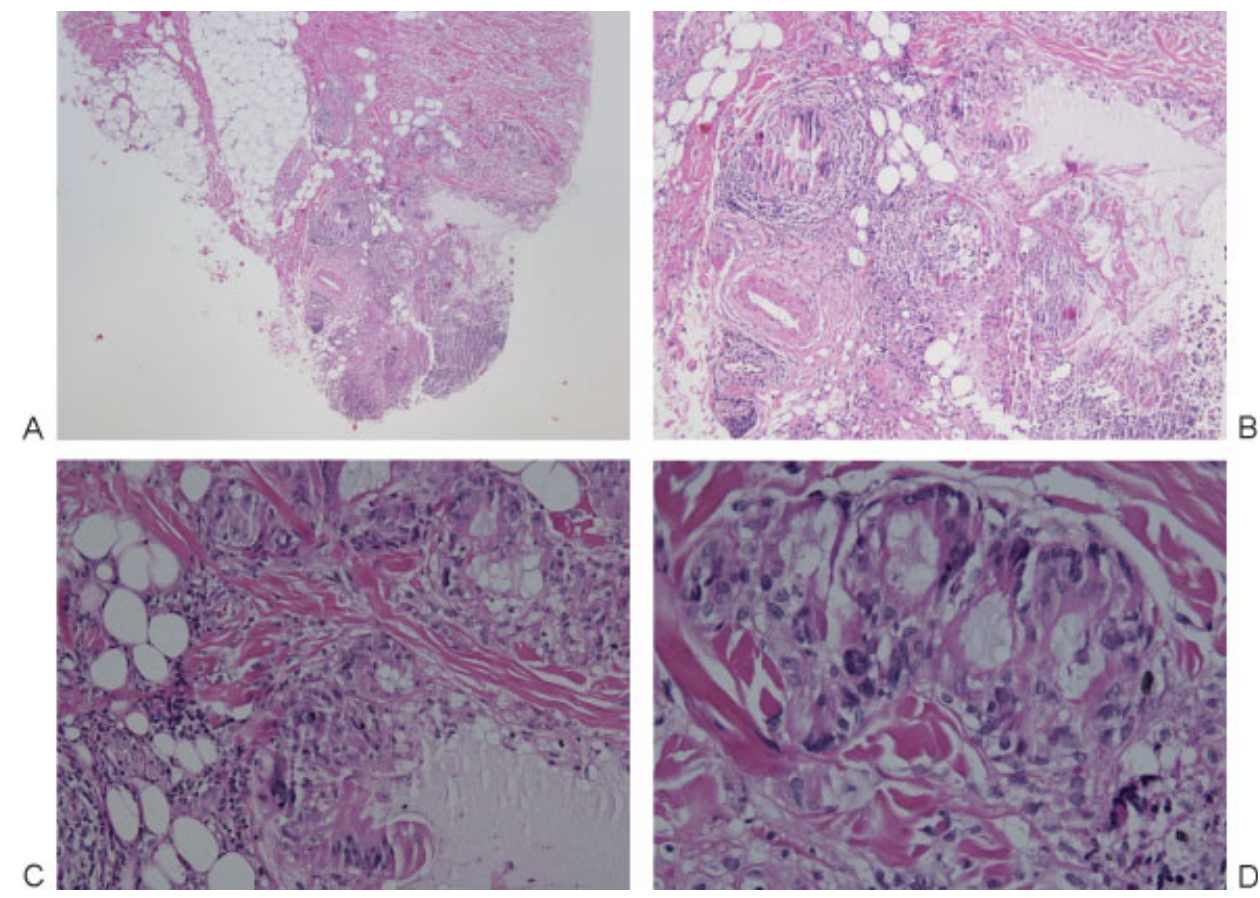

Fig. 8 (A) Granulomatous reaction to polyacrylamide gel in the deep dermis and adjacent cutaneous fat. Hematoxylin-eosin (HE), original magnification $\times 4$. (B) Granulomatous reaction to polyacrylamide gel. HE, original magnification $\times 10$. (C) Granulomatous reaction to polyacrylamide gel. The polyacrylamide gel (PAAG) is seen as a faintly basophilic amorphous substance, but there are also empty spaces resembling fat cells. HE, original magnification $\times 20$. (D) Granulomatous reaction to polyacrylamide gel. The giant cells contain PAAG with small blebs in it. HE, original magnification $\times 40$. 


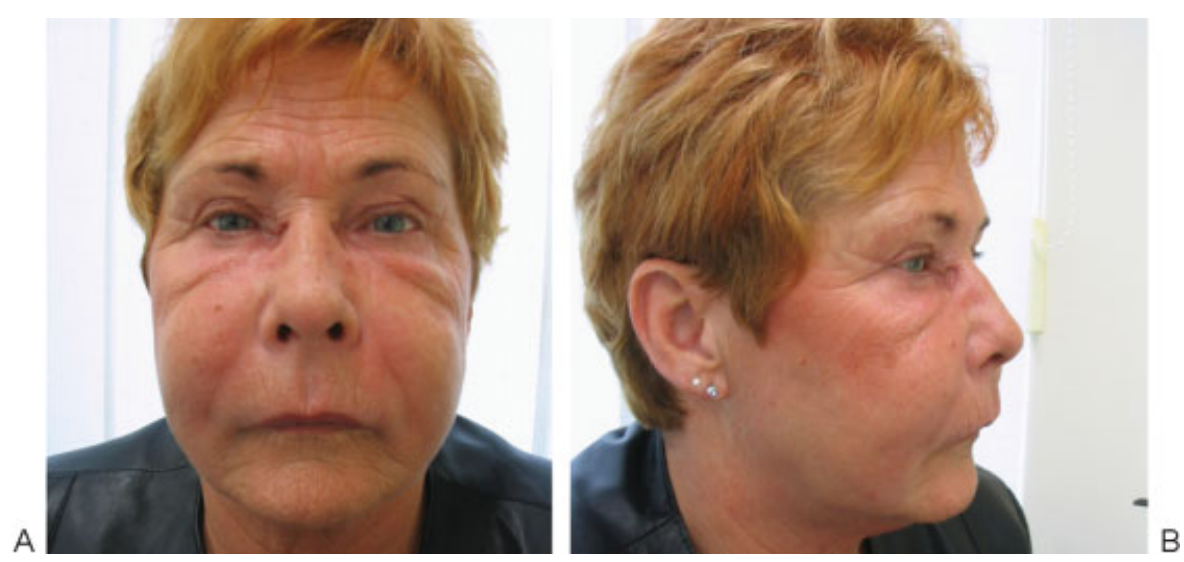

Fig. 9 Bioalcamid (polyalkylimide hydrogel) allergic reaction: massive edema. (A) Frontal view. (B) Side view. (Courtesy: F. Bruyns, the Netherlands).

Polyvinyl Hydroxide Microspheres in Polyacrylamide Gel This filler is a suspension of 6\% polyvinyl hydroxide microspheres in 25\% PAAG hydrogel (Evolution). It is apparently well tolerated though it is not often used..$^{50,85}$

\section{Acrylic Hydrogel}

A suspension of ethyl methacrylate and hydroxyethyl methacrylate particles in HA was marketed under the brand names of DermaLive and DermaDeep. Initially reported as being well tolerated, ${ }^{86}$ it soon turned out that this biphasic filler caused late granulomas in a very high percentage of cases ${ }^{87-89}$ so that it had to be withdrawn from the market. However, granulomas still occur. ${ }^{90}$ They usually present as nodules that are first palpable and then often become visible (-Fig. 9). Fistulation may develop, and even a keratoacanthoma-like appearance was seen. ${ }^{91}$ The granulomas are well delimited and relatively easy to remove surgically; however, new granulomas often develop. Other treatments are intralesional corticosteroids, allopurinol, and 5-fluorouracil. Antibiotics have to be given before if an infection is suspected..$^{92}$ Histopathology shows a dense granuloma with a fibrous pseudocapsule containing masses of crystalloid acrylate particles. The granulomas are made up of epithelioid and foreign body giant cells that try to engulf the particles. Some areas become necrotic and contain cholesterol clefts. Epidermal ridges may grow down and try to surround the foreign material giving rise to fistulae formation. Some granulomas may become sclerotic with time (-Figs. 10 and 11).

\section{Polymethyl Methacrylate}

Artecoll, Artefill, and Artesense are PMMA beads suspended in bovine collagen. Testing of bovine collagen is necessary before use to avoid an immune reaction. Individuals with a history of keloids should not be treated. ${ }^{93}$ Approximately 3 weeks after injection, the body starts depositing own collagen around the microspheres, which get virtually encapsulated by own collagen. Overcorrection is not performed. Artefill has polished microbeads being thought to attract fewer impurities and thus being less prone to induce granuloma formation. ${ }^{94}$ Metacrill and Metrex are also PMMA particles though not round and polished. Although granulo- mas are rare with $0.01 \%$ reported $^{95,96}$ they do occur and are difficult to treat. ${ }^{97}$ Lumps often form, particularly in the lips, but most are just palpable and not visible. Granulomas may develop several years after the injection. ${ }^{98}$ Granuloma precipitation occurred many years after injection when a patient was treated with interferon because of hepatitis $C^{99}$ or laser skin resurfacing was performed over the area of injection (D. Vochelle, MD, personal oral communication). The granulomas appear suddenly with induration, swelling, tenderness, and erythema (-Fig. 12). Histopathology shows a typical granuloma with round empty-appearing clear spaces in a fibrotic tissue. Treatment was performed with intralesional corticosteroids and 5-fluorouracil ${ }^{100}$ as well as allopurinol and surgery. Metacrill granulomas were melted with high-frequency "endocoagulation" leaving a residue of burnt plastic with a characteristic smell. ${ }^{101}$ Intralesional laser treatment is another option. Profill may cause considerable lipodystrophy (-Fig. 13).

\section{Paraffin and Other Mineral Oil and Lipid Derivatives}

Crude substances such as vaseline, paraffin, lanolin, cod liver oil, or beeswax were used in the late 19th and early 20th century. Despite initial satisfying results, long-term results were usually appalling because of skin hardening, swelling, granuloma formation, ulceration and fistulation, infections, abscesses, and even cancer development. ${ }^{1}$

Paraffin is irreversible and no longer legally used as a filler although highly inflammatory granulomas after fraudulent use of paraffin or other oils containing vitamin $E$, sometimes also vitamins $D$ and $A$, are still seen (- Fig. 14). ${ }^{102}$ Injection of paraffin into the penis caused sclerosing lipogranuloma characterized by fibrosis and deformation. ${ }^{103}$ Histopathologically, the deep reticular dermis and subcutaneous fat are involved with a predominantly lobular panniculitis with a Swiss cheese appearance. The cystic spaces are surrounded by foamy histiocytes and giant cells. The collagen bundles inbetween are sclerotic (-Fig. 15).

Vaseline and other mineral oils cause a very similar reaction. $^{104-107}$

Whether ultrasound liquefaction of the fat where the inappropriate substance had been injected, and subsequent 

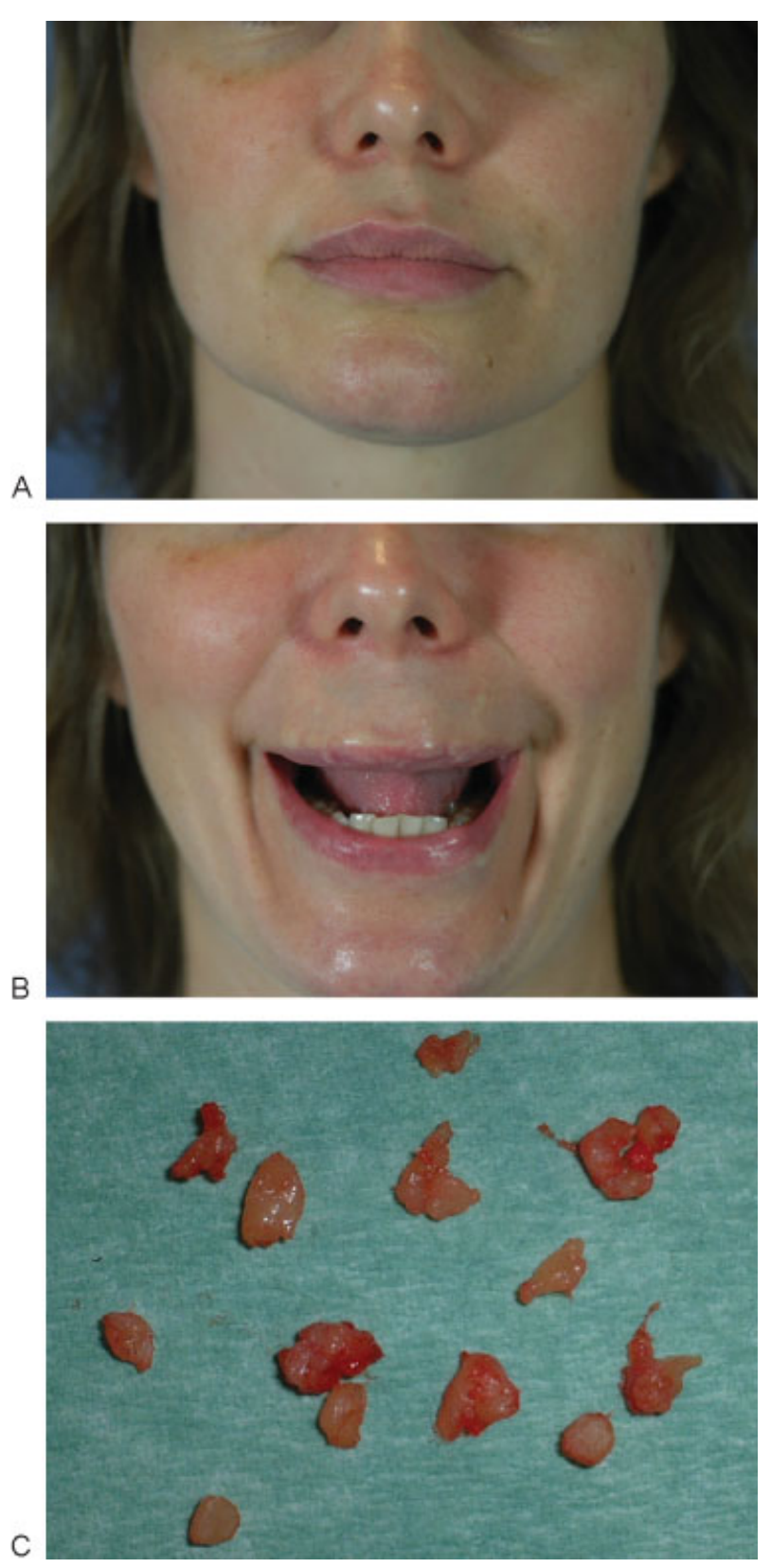

Fig. 10 (A). Small palpable nodules in the lip after HEMA injection (DermaLive) (Klinikk Bunæs, Norway). (B) Stretching the lips makes the nodules visible (Klinikk Bunæs, Norway). (C) Many of the nodules could easily be extirpated from the mucosal side of the lip. (Courtesy: J. Bunæs, Norway).

extraction by a suction cannula helps to eliminate this material remains to be seen. ${ }^{108,109}$

\section{Silicone}

Silicone is another irreversible filler. It is a highly polymerized hydrophobic oil (Silikon 1000 [Alcon Labs, San Diego, CA], Adatosil 5000 [Bausch \& Lomb Surgical Inc., San Dimas, CA], Biopolimero), gel (MDX 4-4011), or solid rubber consisting of dimethylsiloxane units. Silicone is generally well tolerated, but the occasional adverse effects may be dramatic and irreversible; this is the reason why it is banned for cosmetic use both in the European Union as well as the United States. Those still using silicone off-label claim that pure silicone ${ }^{110}$ and proper microdroplet technique prevent adverse effects, but this is not generally accepted. Medical grade silicone oil is pure and sterile (-Fig. 16). The secret of good long-term results appears to be the injection of truly minute amounts. ${ }^{111-113}$ A mixture of silicone with HA was recently described as "the optimal filler." 114

Adverse effects are local and systemic. Minor complications are small nodules seen within a year after injection and are mainly due to too much substance. However, indurations and erythema with swelling are silicone granulomas that often only appear 2 to 12 years after injection. The differentiation between siliconoma, which consists almost exclusively of macrophages containing small droplets of silicone oil and contains virtually no inflammatory cells, and silicone granuloma with silicone containing macrophages, lymphocytes, and giant cells is somewhat artificial. Both respond to intralesional corticosteroids in most cases. Major complications are systemic with pneumonitis, acute respiratory distress syndrome, sudden death after intravascular injection, migration of large volumes of low-viscosity silicone oil, erysipelas-like reactions, blindness, loss of neurologic functions, and death after silicone oil had been inadvertently injected into the ophthalmic or meningeal vessels.

\section{Silicone Elastomer Particles (Bioplastique)}

A silicone elastomer suspension in polyvinylpyrrolidone Plasdone hydrogel was mainly used in urology and for vocal cord augmentation. It was shown to produce both lumps and granulomas. $^{115,116}$

\section{General Features of the Histopathology of Adverse Filler Effects}

Many fillers have a specific morphology and/or staining pattern in the skin. ${ }^{50}$ This is both true for acute reactions when the filler is still visible as well as for late reactions such as granulomas and infections with abscesses.

Bovine collagen is seen as a dense eosinophilic mass in the skin. It is not birefringent in contrast to human collagen fibers. Early "allergic" reactions usually show a lymphocytic infiltrate, which may turn into a granuloma with many epithelioid cells and some intermingled giant cells.

HA may sometimes be seen in the skin as a more or less structureless basophilic substance, this may correspond to the Tyndall effect when localized very superficially. Granulomas were relatively frequently seen in the early times of manufacturing of streptococcal HA, most probably due to the content of protein. This is nowadays very rare with this product. Another new brand caused many granulomas and abscesses. They consisted of a dense lymphocytic infiltrate with many giant cells, often of excessive size, as well as many eosinophils around basophilic HA. In case of abscesses and fistulation, foci of neutrophils are seen.

Matridex (biopolymer, Siershahn, Germany) shows both HA as well as dextranomer beads in a cell-rich granuloma. The microspheres are perfectly round and darkly basophilic or purple allowing the product to be identified. 

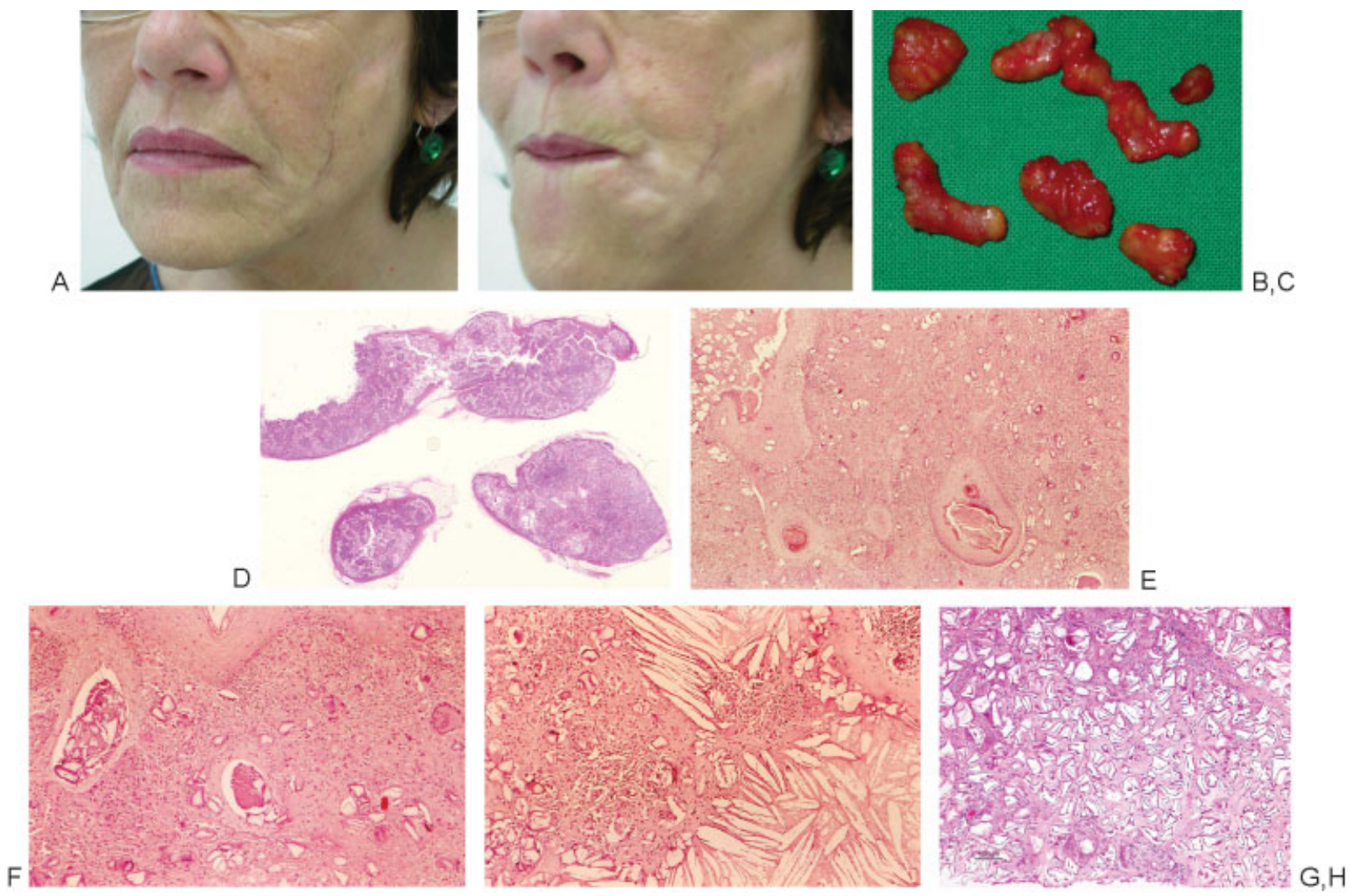

Fig. 11 (A, B) HEMA granulomas 2 years after injection. (C) Some granulomas extirpated from the perioral region. (D) Histopathology of HEMA nodules shows well-delimited granulomas surrounded by a fibrous pseudocapsule. Hematoxylin-eosin (HE) stain, scanning magnification, $\times 4$. (E) HEMA granuloma. There is a dense granulomatous infiltrate with epithelioid cell, some giant cells, many HEMA particles, which stand out by their polygonal appearance, and sinus and fistulae tracks, the latter also containing HEMA particles. HE, $\times 100$. (F) Higher magnification of the vicinity of a sinus with many HEMA particles, monstrous giant cells, and neutrophils. HE, $\times 200$. (G) HEMA granuloma with particles and many slit like, socalled cholesterol clefts. HE, x 200. (H) HEMA granuloma during treatment with intralesional triamcinolone acetonide plus 5-fluorouracil. There is little infiltrate and the connective tissue appears hyalinized. $\mathrm{HE}, \times 200$.

PLL acid is seen as crystalloid material in epithelioid cell granulomas with giant cells often surrounded by fibrosis. The material is birefringent permitting its exact identification.

Acrylic hydrogel mainly causes late granulomas and no HA is seen any more. The acrylic particles are polyhedric and seen in a dense granuloma with giant cells, many of which try to engulf the foreign bodies. Necrotic areas are frequent and often contain cholesterol clefts. Clinically visible fistulae

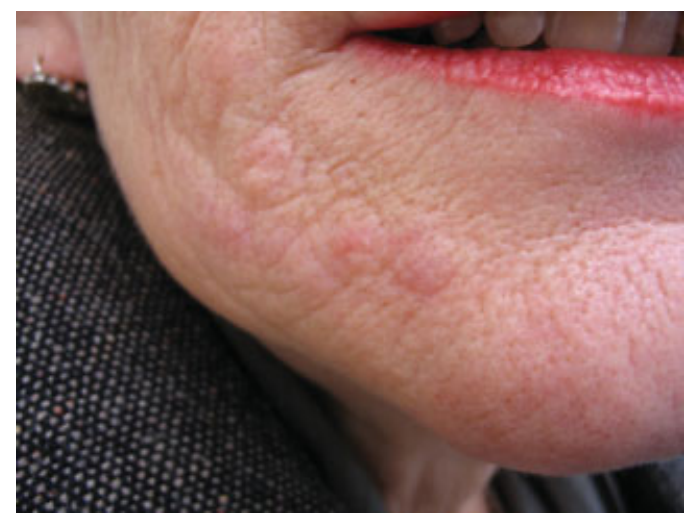

Fig. 12 Granuloma due to polymethyl methacrylate microspheres in collagen (Artecoll) (Courtesy: F. Bruyns, the Netherlands). correspond histopathologically to epidermal ingrowths also trying to engulf and transepidermally eliminate filler material.

Polymethyl methacrylate (Artecoll and Artefill) is seen as round empty-appearing spaces in a fibrotic tissue. Although appearing to be of relatively uniform size this depends on the section plane. In case of granuloma formation, epithelioid and giant cells are seen in addition.

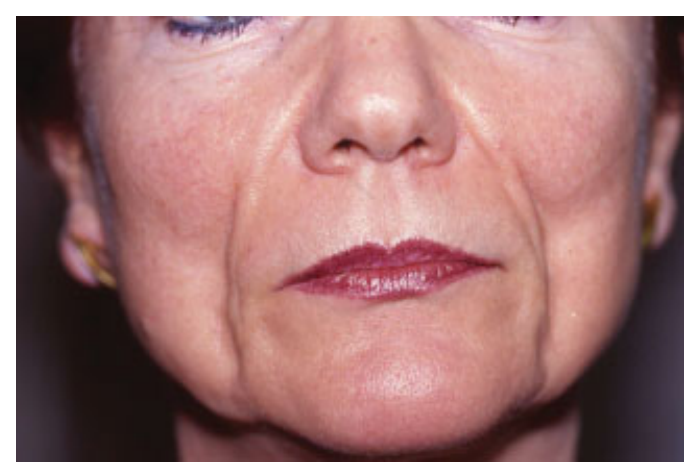

Fig. 13 Late complication of Profill demonstrating serious fat atrophy after initial inflammation. (Courtesy: P. André, France). 


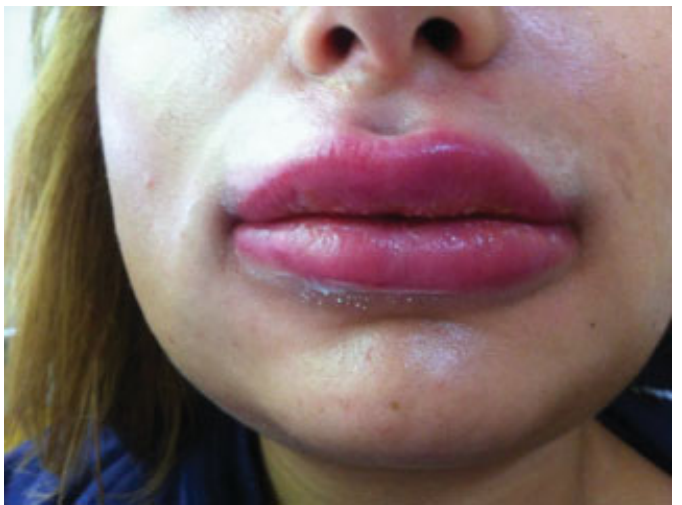

Fig. 14 Intense inflammation beginning 3 weeks after injection of oily vitamin E for lip augmentation (Courtesy: J. Kanzandjieva, Sofia, Bulgaria).

PAAG is very well tolerated biologically. The main risk is infection that may cause abscesses and necroses. Granulomas show epithelioid and giant cells. The material is basophilic and does not exhibit a wavy structure often seen with HA.

A
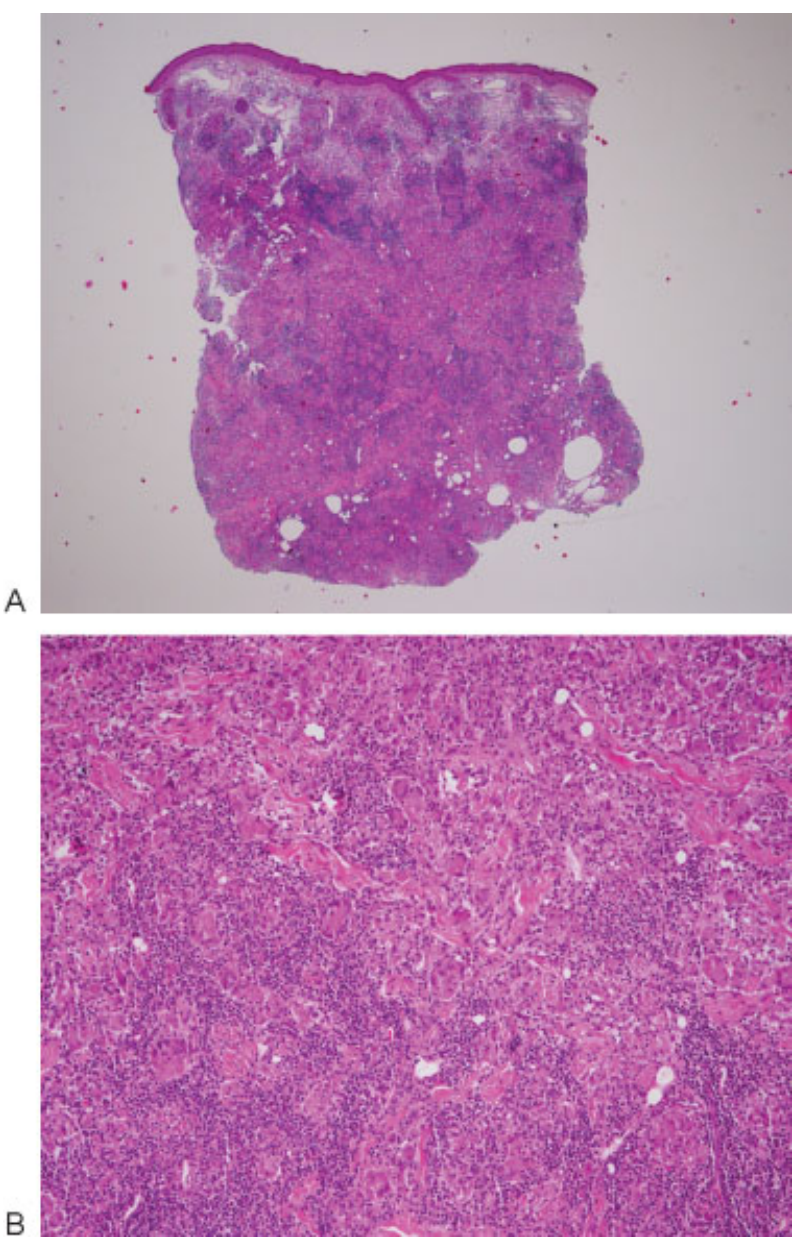

Fig. 15 (A) Scanning magnification of a punch biopsy of a patient who had herself autoinjected material that she had eluted from a hyaluronic acid-containing cream. There is a subepidermal edema and many granulomas all over in the dermis surrounded by lymphocytes (Copyright 2014: Department of Dermatology, Inselspital Bern University Hospital). (B) Many small granulomas are distributed in a dense lymphocytic infiltrate (Copyright 2014: Department of Dermatology, Inselspital Bern University Hospital).
Silicone oil causes granulomas with droplets of varying size, some of which are seen in epithelioid cells. Giant cells are rare as there are no particles. Often dense lymphocytic infiltrates are seen in perivascular localization.

Sclerosing lipogranuloma is a characteristic feature of paraffin injection, mainly in the penis to increase its girth. It is characterized by a Swiss cheese like aspect in a fibrotic tissue with lymphocytes, epithelioid, and giant cells. The empty spaces are of variable size.

The injection of vitamin $\mathrm{E}$ in different oils gives a similar histopathological picture, but as these injections are now mainly made in the face, particularly in the lips, by nonmedical persons the changes are much more acute and the inflammatory component is more obvious in these cases.

\section{Imaging Techniques}

Several imaging techniques were applied to aid in the diagnosis of filler complications, particularly in the diagnosis of suspected abscesses. Further indications are overfilling, migration, foreign-body granulomas, and scarring. ${ }^{117}$ Using high-frequency ultrasound complemented with magnetic resonance imaging (MRI) and white blood cell scintigraphy, allowed the distinction between infections, fibrosis, granulomatous inflammation, and product migration. ${ }^{118}$ Calcium hydroxyapatite is radio-opaque and can be seen in normal radiographs ${ }^{119}$; however, its injection may cause local hypermetabolism and thus be a source of false-positive findings in positron emission tomography scans. ${ }^{120,121}$ Using conventional X-ray films, computed tomography, and MRI techniques, a distinction of different materials frequently may be feasible. ${ }^{122}$

\section{General Treatment Remarks}

Prevention is always better and easier than treatment-this rationale is also true for filler adverse effects. After identifying the exact nature of an adverse effect, the appropriate therapy has to be chosen. Early adverse effects such as injection pain, immediate swelling, and edema usually do not require specific treatment. Cooling is often sufficient to alleviate the immediate postinjection pain; however, this is rarely seen anymore as more and more preparations contain a local anesthetic. Swelling may respond to acetylsalicylic acid (Aspirin [Bayer, Leverkusen, Germany]) or another nonsteroidal anti-inflammatory drug. Placement of too much material or in the wrong area requires immediate massage or removal, if possible. Lump formation after calcium hydroxyl apatite injection in the lip is a technical fault as well as too superficial an injection. Proper training before starting to inject is mandatory.

Blanching extending beyond the immediate area of the injection volume may be a sign of vascular occlusion. Nitroglycerin cream and warming may be sufficient in mild cases. $^{13}$

HA can de-dissolved with hyaluronidase. Most preparations are of animal origin and there is the theoretical possibility of a sensitization. It is wise to use one preparation to get experience with it as the dosage may vary among the different drugs. The effect is usually seen within hours, and 

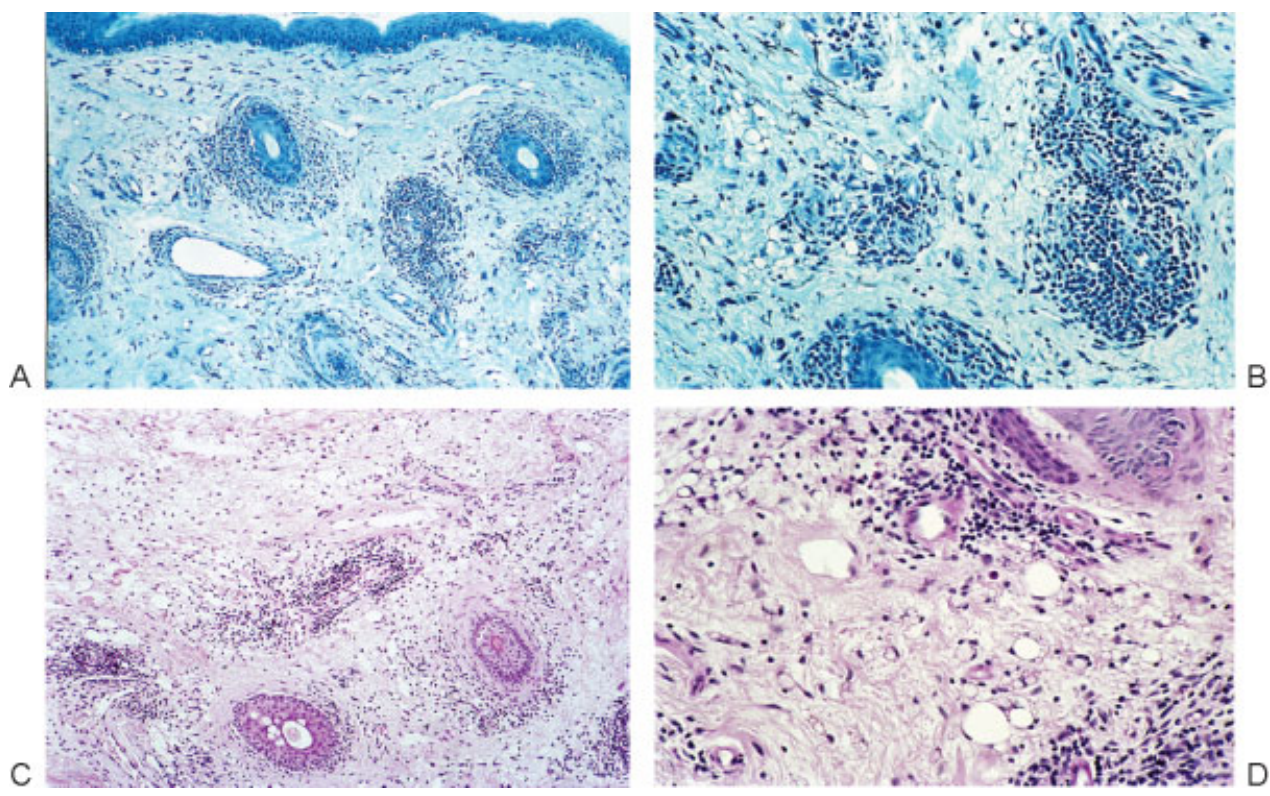

Fig. 16 Siliconoma. (A) Perivascular lymphocytic infiltrates and an edematous reticular dermis. Methylene blue stain $\times 100$. (B) There are dense perivascular lymphocytic infiltrates and some relatively small, round, empty-appearing spaces. Methylene blue stain $\times 200$. (C,D) The connective tissue is very loose with many barely visible round spaces that are smaller than normal fat cells. Cresyl violet (C) $\times 100,(D) \times 200$.

reinjection is possible after 24 hours, so small doses are recommended in the beginning.

The problem is the treatment of late and delayed adverse effects. First, the responsible substance has to be identified. This is often impossible as the patients do not know, or are reluctant to disclose, which filler had been injected. Once a granuloma has developed it is to be assumed that granulomas will continue to develop as long as the foreign material is in the skin. Whether attenuated total reflectance/Fourier transform infrared analysis spectroscopy ${ }^{123}$ really allows fillers to be reliably identified remains to be seen. Another validated method is the histological examination of sections, which yield quite specific changes with most different fillers. ${ }^{50,124}$

The differentiation of infection from noninfectious granulomas is possible with radioactive labeled leukocytes. In case of infection, antibiotics have to be given long enough and in doses capable of containing the infection. Staphylococcus fast antibiotics such as cephalosporins are given intravenously. ${ }^{125}$ Vancomycin (Pfizer, Munich, Germany) is administered for Staph epidermidis.

Granulomas often respond to an intralesional injection of a mixture of $250 \mathrm{mg}$ 5-fluorouracil/ $\mathrm{mL}, 10 \mathrm{mg}$ triamcinolone acetonide/mL plus mepivacaine $1 \mathrm{~mL}$, which is given first twice, then once weekly, ${ }^{126}$ plus allopurinol 300 to $600 \mathrm{mg} /$ d. ${ }^{127}$ Tumor necrosis factor $\alpha$ inhibitors have not yet gained much acceptance in the treatment of granulomas. In progressive cases where all conservative treatment options fail, surgical removal may be inevitable.

\section{Conclusion}

Fillers belong to the most frequently used substances in esthetic medicine. The "consumers" are not sick patients, but they are healthy persons expecting to look better after the procedure. Any adverse effect, whether immediate, late or delayed, temporary or irreversible, is a catastrophe for them and potentially for the treating physician. All measures have to be taken to avoid them: The physician must be well trained, use the best product, respect indications, contraindications, proper aseptic injection techniques, and adequate localization for each specific filler. The patient has to follow the physician's recommendations after treatment. The best would be to give a "filler pass" to the patient that notes which filler was when and where injected. Despite all precautions, adverse effects may occur. Take them seriously and never dismiss a patient's concerns. Treatment should be instituted as soon as possible.

\section{References}

1 Haneke E. Risks of permanent fillers. Expert Rev Dermatol 2009; 4:271-283

2 Haneke E. Skin rejuvenation without a scalpel. I. Fillers. J Cosmet Dermatol 2006;5(2):157-167

3 DeLorenzi C. Complications of injectable fillers, part I. Aesthet Surg J 2013;33(4):561-575

4 Ionescu A, Wutscher E, Brambilla E, Schneider-Feyrer S, Giessibl FJ, Hahnel S. Influence of surface properties of resin-based composites on in vitro Streptococcus mutans biofilm development. Eur J Oral Sci 2012;120(5):458-465

5 Haneke E. Soft tissue augmentation with injectable fillers and implants. In: Vuyk HD, Lohuis PJFM, eds. Facial Plastic Surgery. London: Hodder Arnold; 2006:167-180

6 André P, Lowe NJ, Parc A, Clerici TH, Zimmermann U. Adverse reactions to dermal fillers: a review of European experiences. J Cosmet Laser Ther 2005;7(3-4):171-176

7 Cohen JL. Understanding, avoiding, and managing dermal filler complications. Dermatol Surg 2008;34(Suppl 1):S92-S99

8 Lazzeri D, Agostini T, Figus M, Nardi M, Pantaloni M, Lazzeri S. Blindness following cosmetic injections of the face. Plast Reconstr Surg 2012;129(4):995-1012 
9 Park SW, Woo SJ, Park KH, Huh JW, Jung C, Kwon OK. Iatrogenic retinal artery occlusion caused by cosmetic facial filler injections. Am J Ophthalmol 2012;154(4):653-662.e1

10 Glaich AS, Cohen JL, Goldberg LH. Injection necrosis of the glabella: protocol for prevention and treatment after use of dermal fillers. Dermatol Surg 2006;32(2):276-281

11 Hirsch RJ, Cohen JL, Carruthers JD. Successful management of an unusual presentation of impending necrosis following a hyaluronic acid injection embolus and a proposed algorithm for management with hyaluronidase. Dermatol Surg 2007;33(3): 357-360

12 Narins RS, Jewell M, Rubin M, Cohen J, Strobos J. Clinical conference: management of rare events following dermal fillers-focal necrosis and angry red bumps. Dermatol Surg 2006;32(3): 426-434

13 Kleydman K, Cohen JL, Marmur E. Nitroglycerin: a review of its use in the treatment of vascular occlusion after soft tissue augmentation. Dermatol Surg 2012;38(12):1889-1897

14 Fulton J, Caperton C, Weinkle S, Dewandre L. Filler injections with the blunt-tip microcannula. J Drugs Dermatol 2012;11(9): 1098-1103

15 Fiore R II, Miller R, Coffman SM. Mycobacterium mucogenicum infection following a cosmetic procedure with poly-L-lactic acid.J Drugs Dermatol 2013;12(3):353-357

16 Christensen L, Breiting V, Bjarnsholt T, et al. Bacterial infection as a likely cause of adverse reactions to polyacrylamide hydrogel fillers in cosmetic surgery. Clin Infect Dis 2013;56(10): 1438-1444

17 Beljaards RC, de Roos KP, Bruins FG. NewFill for skin augmentation: a new filler or failure? Dermatol Surg 2005;31(7 Pt 1): 772-776, discussion 776

18 Rohrich RJ, Monheit G, Nguyen AT, Brown SA, Fagien S. Soft-tissue filler complications: the important role of biofilms. Plast Reconstr Surg 2010;125(4):1250-1256

19 Gleeson CM, Lucas S, Langrish CJ, Barlow RJ. Acute fatal fat tissue embolism after autologous fat transfer in a patient with lupus profundus. Dermatol Surg 2011;37(1):111-115

20 Weinkle S. Efficacy and tolerability of admixing $0.3 \%$ lidocaine with Dermicol-P35 27G for the treatment of nasolabial folds. Dermatol Surg 2010;36(3):316-320

21 Sclafani AP, Romo T III. Collagen, human collagen, and fat: the search for a three-dimensional soft tissue filler. Facial Plast Surg 2001;17(1):79-85

22 Bassetto F, Turra G, Salmaso R, Lancerotto L, Del Vecchio DA. Autologous injectable dermis: a clinical and histological study. Plast Reconstr Surg 2013;131(4):589e-596e

23 Saray A. Porcine dermal collagen (Permacol) for facial contour augmentation: preliminary report. Aesthetic Plast Surg 2003; 27(5):368-375

24 Monstrey SJ, Pitaru S, Hamdi M, et al. A two-stage phase I trial of Evolence30 collagen for soft-tissue contour correction. Plast Reconstr Surg 2007;120(1):303-311

25 Braun M, Braun S. Nodule formation following lip augmentation using porcine collagen-derived filler.J Drugs Dermatol 2008;7(6): 579-581

26 Clark CP III. Animal-based hyaluronic acid fillers: scientific and technical considerations. Plast Reconstr Surg 2007;120(6, Suppl) 27S-32S

27 Mummert ME. Immunologic roles of hyaluronan. Immunol Res 2005;31(3):189-206

28 Stern R, Asari AA, Sugahara KN. Hyaluronan fragments: an information-rich system. Eur J Cell Biol 2006;85(8):699-715

29 Wright AJ, Day AJ. Hyaluronan in immune processes. Adv Exp Med Biol 2005;564:57-69

30 Goomer RS, Leslie K, Maris T, Amiel D. Native hyaluronan produces less hypersensitivity than cross-linked hyaluronan. Clin Orthop Relat Res 2005;(434):239-245
31 Enríquez Merino J. Perhidroescualeno y colágeno-polivinilpirrolidona: un nuevo matrial de relleno. Ensayo clínico con 20 pcientes. Dermatol Cosm Med Quir 2013;11:19-22

32 Escobar Francisco SA, Rodríguez Ruiz XC. Tratamiento de surcos, depresiones cutáneas y líneas de expresión con perhidroescualeno CLG-PVP. Dermatol Cosm Méd Quir 2013;11:104-111

33 Figueiredo VM. A five-patient prospective pilot study of a polycaprolactone based dermal filler for hand rejuvenation. J Cosmet Dermatol 2013;12(1):73-77

34 de Melo F, Marijnissen-Hofsté J. Investigation of physical properties of a polycaprolactone dermal filler when mixed with lidocaine and lidocaine/epinephrine. Dermatol Ther (Heidelb) 2012; 2(1):13

35 Moulonguet I, de Goursac C, Plantier F. Granulomatous reaction after injection of a new resorbable filler Novabel. Am J Dermatopathol 2011;33(7):710-711

36 Niamtu J III. Filler injection with micro-cannula instead of needles. Dermatol Surg 2009;35(12):2005-2008

37 Rodriguez JM, Xie YL, Winthrop KL, et al. Mycobacterium chelonae facial infections following injection of dermal filler. Aesthet Surg J 2013;33(2):265-269

38 Grippaudo FR, Pacilio M, Di Girolamo M, Dierckx RA, Signore A. Radiolabelled white blood cell scintigraphy in the work-up of dermal filler complications. Eur J Nucl Med Mol Imaging 2013; 40(3):418-425

39 Colbert SD, Southorn BJ, Brennan PA, Ilankovan V. Perils of dermal fillers. Br Dent J 2013;214(7):339-340

40 Alijotas-Reig J, Fernández-Figueras MT, Puig L. Inflammatory, immune-mediated adverse reactions related to soft tissue dermal fillers. Semin Arthritis Rheum 2013;43(2):241-258

41 Talbot SG, Parrett BM, Yaremchuk MJ. Sepsis after autologous fat grafting. Plast Reconstr Surg 2010;126(4):162e-164e

42 Sykes JM, Tapias V, Pu LL. Autologous fat grafting viability: lower third of the face. Facial Plast Surg 2010;26(5):376-384

43 Taupin A, Labbé D, Nicolas J, Debout C, Benateau H. Lipofilling and weight gain. Case report and review of the literature [in French]. Ann Chir Plast Esthet 2010;55(3):238-242

44 Delay E, Garson S, Tousson G, Sinna R. Fat injection to the breast: technique, results, and indications based on 880 procedures over 10 years. Aesthet Surg J 2009;29(5):360-376

45 Teimourian B. Blindness following fat injections. Plast Reconstr Surg 1988;82(2):361

46 Dreizen NG, Framm L. Sudden unilateral visual loss after autologous fat injection into the glabellar area. Am J Ophthalmol 1989; 107(1):85-87

47 w? cerebral artery embolism and unilateral visual loss after autologous fat injection into the glabellar area. Stroke 1993;24(4): 615-616

48 Feinendegen DL, Baumgartner RW, Vuadens P, et al. Autologous fat injection for soft tissue augmentation in the face: a safe procedure? Aesthetic Plast Surg 1998;22(3):163-167

49 Sclafani AP, Romo T III, Jacono AA, McCormick S, Cocker R, Parker A. Evaluation of acellular dermal graft in sheet (AlloDerm) and injectable (micronized AlloDerm) forms for soft tissue augmentation. Clinical observations and histological analysis. Arch Facial Plast Surg 2000;2(2):130-136

50 Requena L, Requena C, Christensen L, Zimmermann US, Kutzner $\mathrm{H}$, Cerroni L. Adverse reactions to injectable soft tissue fillers. J Am Acad Dermatol 2011;64(1):1-34, quiz 35-36

51 Tutrone WD, Cohen JL. Dissolving collagen fillers: enzymatic degradation of some problematic filler circumstances may now include collagens. J Drugs Dermatol 2009;8(12):1140-1141

52 André P. Evaluation of the safety of a non-animal stabilized hyaluronic acid (NASHA - Q-Medical, Sweden) in European countries: a retrospective study from 1997 to 2001. J Eur Acad Dermatol Venereol 2004;18(4):422-425 
53 Rodrigues-Barata AR, Camacho-Martínez FM. Undesirable effects after treatment with dermal fillers. J Drugs Dermatol 2013;12(4): e59-e62

54 Buntrock H, Reuther T, Prager W, Kerscher M. Efficacy, safety, and patient satisfaction of a monophasic cohesive polydensified matrix versus a biphasic nonanimal stabilized hyaluronic acid filler after single injection in nasolabial folds. Dermatol Surg 2013;39(7):1097-1105

55 Micheels P. Human anti-hyaluronic acid antibodies: is it possible? Dermatol Surg 2001;27(2):185-191

56 Lupton JR, Alster TS. Cutaneous hypersensitivity reaction to injectable hyaluronic acid gel. Dermatol Surg 2000;26(2): 135-137

57 Altman RD, Moskowitz R; Hyalgan Study Group. Intraarticular sodium hyaluronate (Hyalgan) in the treatment of patients with osteoarthritis of the knee: a randomized clinical trial. J Rheumatol 1998;25(11):2203-2212

58 Calvo M, Tornero P, De Barrio M, et al. Erytema multiform due to hyaluronic acid (go-on). J Investig Allergol Clin Immunol 2007; 17(2):127-128

59 Brody HJ. Use of hyaluronidase in the treatment of granulomatous hyaluronic acid reactions or unwanted hyaluronic acid misplacement. Dermatol Surg 2005;31(8, Pt 1):893-897

60 Bachmann F, Erdmann R, Hartmann V, Wiest L, Rzany B. The spectrum of adverse reactions after treatment with injectable fillers in the glabellar region: results from the Injectable Filler Safety Study. Dermatol Surg 2009;35(Suppl 2):1629-1634

61 Schuller-Petrović S, Pavlović MD, Schuller SS, Schuller-Lukić B, Neuhold N. Early granulomatous foreign body reactions to a novel alginate dermal filler: the system's failure? J Eur Acad Dermatol Venereol 2013;27(1):121-123

62 Eppley BL, Summerlin DJ, Prevel CD, Sadove AM. Effects of a positively charged biomaterial for dermal and subcutaneous augmentation. Aesthetic Plast Surg 1994;18(4):413-416

63 Massone C, Horn M, Kerl H, Ambros-Rudolph CM, Giovanna Brunasso AM, Cerroni L. Foreign body granuloma due to Matridex injection for cosmetic purposes. Am J Dermatopathol 2009;31(2): 197-199

64 Huh SY, Cho S, Kim KH, et al. A case of complication after matridex (r) injection. Ann Dermatol 2010;22(1):81-84

65 Yang J-H, Lee SM, Won C-H, et al. Foreign body granuloma caused by hyaluronic acid/dextranomer microsphere filler injection. Int J Dermatol 2012;51(12):1517-1518

66 Apikian M, Roberts S, Goodman GJ. Adverse reactions to polylactic acid injections in the periorbital area. J Cosmet Dermatol 2007;6(2):95-101

67 Palm MD, Woodhall KE, Butterwick KJ, Goldman MP. Cosmetic use of poly-l-lactic acid: a retrospective study of 130 patients. Dermatol Surg 2010;36(2):161-170

68 Zimmermann US, Clerici TJ. The histological aspects of fillers complications. Semin Cutan Med Surg 2004;23(4):241-250

69 Marmur ES, Al Quran H, De Sa Earp AP, Yoo JY. A five-patient satisfaction pilot study of calcium hydroxylapatite injection for treatment of aging hands. Dermatol Surg 2009;35(12):1978-1984

70 Daines SM, Williams EF III. Complications associated with injectable soft-tissue fillers: a 5-year retrospective review. JAMA Facial Plast Surg 2013;15(3):226-231

71 Daley T, Damm DD, Haden JA, Kolodychak MT. Oral lesions associated with injected hydroxyapatite cosmetic filler. Oral Surg Oral Med Oral Pathol Oral Radiol 2012;114(1):107-111

72 Dadzie OE, Mahalingam M, Parada M, El Helou T, Philips T, Bhawan J. Adverse cutaneous reactions to soft tissue fillers-a review of the histological features. J Cutan Pathol 2008;35(6): 536-548

73 Reddy KK, Brauer JA, Anolik R, et al. Calcium hydroxylapatite nodule resolution after fractional carbon dioxide laser therapy. Arch Dermatol 2012;148(5):634-636
74 Cohen JC, Reisacher W, Malone M, Sulica L. Severe systemic reaction from calcium hydroxylapatite vocal fold filler. Laryngoscope 2013;123(9):2237-2239

75 Christensen LH, Breiting VB, Aasted A, Jørgensen A, Kebuladze I. Long-term effects of polyacrylamide hydrogel on human breast tissue. Plast Reconstr Surg 2003;111(6):1883-1890

76 Leung KM, Yeoh GPS, Chan KW. Breast pathology in complications associated with polyacrylamide hydrogel (PAAG) mammoplasty. Hong Kong Med J 2007;13(2):137-140

77 Kalantar-Hormozi A, Mozafari N, Rasti M. Adverse effects after use of polyacrylamide gel as a facial soft tissue filler. Aesthet Surg J 2008;28(2):139-142

78 Reda-Lari A. Augmentation of the malar area with polyacrylamide hydrogel: experience with more than 1300 patients. Aesthet Surg J 2008;28(2):131-138

79 Cheng NX, Wang YL, Wang JH, Zhang XM, Zhong H. Complications of breast augmentation with injected hydrophilic polyacrylamide gel. Aesthetic Plast Surg 2002;26(5):375-382

80 Lee CJ, Kim SG, Kim L, Choi MS, Lee SI. Unfavorable findings following breast augmentation using injected polyacrylamide hydrogel. Plast Reconstr Surg 2004;114(7):1967-1968

81 Zarini E, Supino R, Pratesi G, et al. Biocompatibility and tissue interactions of a new filler material for medical use. Plast Reconstr Surg 2004;114(4):934-942

82 Malik S, Mehta P, Adesanya O, Ahluwalia HS. Migrated periocular filler masquerading as arteriovenous malformation: a diagnostic and therapeutic dilemma. Ophthal Plast Reconstr Surg 2013; 29(1):e18-e20

83 Jones DH, Carruthers A, Fitzgerald R, Sarantopoulos GP, Binder S. Late-appearing abscesses after injections of nonabsorbable hydrogel polymer for HIV-associated facial lipoatrophy. Dermatol Surg 2007;33(Suppl 2):S193-S198

84 Goldan O, Georgiou I, Grabov-Nardini G, et al. Early and late complications after a nonabsorbable hydrogel polymer injection: a series of 14 patients and novel management. Dermatol Surg 2007;33(Suppl 2):S199-S206, discussion S206

85 Lemperle G, Morhenn V, Charrier U. Human histology and persistence of various injectable filler substances for soft tissue augmentation. Aesthetic Plast Surg 2003;27(5):354-366, discussion 367

86 Bergeret-Galley C, Latouche X, Illouz YG. The value of a new filler material in corrective and cosmetic surgery: DermaLive and DermaDeep. Aesthetic Plast Surg 2001;25(4):249-255

87 Sidwell RU, Dhillon AP, Butler PE, Rustin MH. Localized granulomatous reaction to a semi-permanent hyaluronic acid and acrylic hydrogel cosmetic filler. Clin Exp Dermatol 2004;29(6):630-632

88 Angus JE, Affleck AG, Leach IH, Millard LG. Two cases of delayed granulomatous reactions to the cosmetic filler Dermalive, a hyaluronic acid and acrylic hydrogel. Br J Dermatol 2006; 155(5):1077-1078

89 Rossner M, Rossner F, Bachmann F, Wiest L, Rzany B. Risk of severe adverse reactions to an injectable filler based on a fixed combination of hydroxyethylmethacrylate and ethylmethacrylate with hyaluronic acid. Dermatol Surg 2009;35(Suppl 1):367-374

90 González-Vela MC, Armesto S, González-López MA, FernándezLlaca JH, Val-Bernal JF. Perioral granulomatous reaction to Dermalive. Dermatol Surg 2008;34(7):986-988

91 Gamo R, Pinedo F, Vicente J, et al. Keratoacanthoma-like reaction after a hyaluronic acid and acrylic hydrogel cosmetic filler. Dermatol Surg 2008;34(7):954-959

92 Weyand B, Menke H. Case report: Adverse granulomatous reaction (granuloma formation) and pseudomonas superinfection after lip augmentation by the new filler DermaLive. Eur J Plast Surg 2008;30:291-295

93 Hoffman AS. Synthetic polymeric biomaterials. In: Gebelein CG, ed. Polymeric Materials and Artificial Organs. Washington, DC: American Chemical Society; 1984:13-29 
94 Dansereau A, Hamilton D, Kavouni A, et al. A report on the safety of and satisfaction with particle-based fillers, specifically polymethylmethacrylate microspheres suspended in collagen. Cos Derm 2008;21:151-156

95 Cohen SR, Berner CF, Busso M, et al. ArteFill: a long-lasting injectable wrinkle filler material-summary of the U.S. Food and Drug Administration trials and a progress report on 4- to 5-year outcomes. Plast Reconstr Surg 2006;118(Suppl 3): S64-S76

96 Solomon P, Sklar M, Zener R. Facial soft tissue augmentation with Artecoll( $(\circledR)$ : A review of eight years of clinical experience in 153 patients. Can J Plast Surg 2012;20(1):28-32

97 Haneke E. Polymethyl methacrylate microspheres in collagen. Semin Cutan Med Surg 2004;23(4):227-232

$98 \mathrm{Wu}$ W, Chayavichitsilp P, Hata T. Extremely delayed granulomatous reaction to soft-tissue injectables (polymethyl methacrylate). J Am Acad Dermatol 2012;67(5):e206-e207

99 Fischer J, Metzler G, Schaller M. Cosmetic permanent fillers for soft tissue augmentation: a new contraindication for interferon therapies. Arch Dermatol 2007;143(4):507-510

100 Conejo-Mir JS, Sanz Guirado S, Angel Muñoz M. Adverse granulomatous reaction to Artecoll treated by intralesional 5-fluorouracil and triamcinolone injections. Dermatol Surg 2006;32(8): 1079-1081, discussion 1082

101 Odo ME, Odo LM, Nemoto NCF, Cucé LC. Treatment of nodules caused by polymethacrylate. A pilot study. Dermatol Surg 2008; 32:1079-1081

102 Kamoona B, Kazandjieva J, Balabanova M, et al. Oil soluble vitamins - unusual use as fillers for lip augmentation. 5th Summer Academy Dermatology Aesthetic Medicine; Sofia, Bulgaria; 2013

103 Foucar E, Downing DT, Gerber WL. Sclerosing lipogranuloma of the male genitalia containing vitamin E: a comparison with classical "paraffinoma”. J Am Acad Dermatol 1983;9(1):103-110

104 Akkus E, Iscimen A, Tasli L, Hattat H. Paraffinoma and ulcer of the external genitalia after self-injection of vaseline. J Sex Med 2006; 3(1):170-172

105 Nyirády P, Kelemen Z, Kiss A, Bánfi G, Borka K, Romics I. Treatment and outcome of vaseline-induced sclerosing lipogranuloma of the penis. Urology 2008;71(6):1132-1137

106 Al-Ansari AA, Shamsodini A, Talib RA, Gul T, Shokeir AA. Subcutaneous cod liver oil injection for penile augmentation: review of literature and report of eight cases. Urology 2010;75(5): 1181-1184

107 Hohaus K, Bley B, Köstler E, Schönlebe J, Wollina U. Mineral oil granuloma of the penis. J Eur Acad Dermatol Venereol 2003; 17(5):585-587

108 Maxwell GP, Gingrass MK. Ultrasound-assisted lipoplasty: a clinical study of 250 consecutive patients. Plast Reconstr Surg 1998;101(1):189-202, discussion 203-204

109 Zocchi ML. Ultrasonic assisted lipoplasty. Technical refinements and clinical evaluations. Clin Plast Surg 1996;23(4):575-598

110 Seward AC, Meara DJ. Industrial-grade silicone injections causing intermittent bilateral malar swelling: review of safety and effica- cy of techniques and products available. J Oral Maxillofac Surg 2013;71(7):1245-1248

111 Webster RC, Fuleihan NS, Hamadan US, Gaunt IM, Smith RC. Injectable silicone: report of 17,000 facial treatments since 1962 . Am J Cosmet Surg 1986;3:41-48

112 Benedetto AV, Lewis AT. Injecting 1000 centistoke liquid silicone with ease and precision. Dermatol Surg 2003;29(3):211-214

113 Zappi E, Barnett JG, Zappi M, Barnett CR. The long-term host response to liquid silicone injected during soft tissue augmentation procedures: a microscopic appraisal. Dermatol Surg 2007;33 (Suppl 2):S186-S192, discussion S192

114 Fulton J, Caperton C. The optimal filler: immediate and long-term results with emulsified silicone (1,000 centistokes) with crosslinked hyaluronic acid. J Drugs Dermatol 2012;11(11):1336-1341

115 Eppley BL, Sidner RA, Sadove AM. Adequate preclinical testing of bioplastique injectable material? Plast Reconstr Surg 1992;89(1): 157-158

116 Baijens L, Speyer R, Linssen M, Ceulen R, Manni JJ. Rejection of injectable silicone "Bioplastique" used for vocal fold augmentation. Eur Arch Otorhinolaryngol 2007;264(5):565-568

117 Ginat DT, Schatz CJ. Imaging of facial fillers: additional insights. AJNR Am J Neuroradiol 2012;33(11):E140-E141

118 Grippaudo FR, Di Girolamo M, Mattei M, Pucci E, Grippaudo C. Diagnosis and management of dermal filler complications in the perioral region. J Cosmet Laser Ther 2014;16(5):246-252

119 El-Halaby A, Furtado Araújo MV. Unusual radiographic finding during routine periodontal maintenance: a case report. Tex Dent J 2014;131(4):297-300

120 Damrose EJ. Radiographic properties of injected calcium hydroxylapatite: potential false positive findings on positron emission tomography. J Laryngol Otol 2008;122(12):1394-1396

121 Feeney JN, Fox JJ, Akhurst T. Radiological impact of the use of calcium hydroxylapatite dermal fillers. Clin Radiol 2009;64(9): 897-902

122 Ginat DT, Schatz CJ. Imaging features of midface injectable fillers and associated complications. AJNR Am J Neuroradiol 2013; 34(8):1488-1495

123 Persichetti P, Palazzolo D, Tenna S, Poccia I, Abbruzzese F, Trombetta M. Dermal filler complications from unknown biomaterials: identification by attenuated total reflectance spectroscopy. Plast Reconstr Surg 2013;131(4):597e-603e

124 Eversole R, Tran K, Hansen D, Campbell J. Lip augmentation dermal filler reactions, histopathologic features. Head Neck Pathol 2013;7(3):241-249

125 Choi HJ. Pseudocyst of the neck after facial augmentation with liquid silicone injection. J Craniofac Surg 2014;25(5):e474-e475

126 Wiest LG, Stolz W, Schroeder JA. Electron microscopic documentation of late changes in permanent fillers and clinical management of granulomas in affected patients. Dermatol Surg 2009;35 (Suppl 2):1681-1688

127 Reisberger EM, Landthaler M, Wiest L, Schröder J, Stolz W. Foreign body granulomas caused by polymethylmethacrylate microspheres: successful treatment with allopurinol. Arch Dermatol 2003;139(1):17-20 